\title{
Liquidity Risk, Return Predictability, and Hedge Funds' Performance: An Empirical Study
}

\author{
Rajna Gibson Brandon and Songtao Wang*
}

\begin{abstract}
This article analyzes the effect of liquidity risk on the performance of equity hedge fund portfolios. Similarly to Avramov, Kosowski, Naik, and Teo (2007), (2011), we observe that, before accounting for the effect of liquidity risk, hedge fund portfolios that incorporate predictability in managerial skills generate superior performance. This outperformance disappears or weakens substantially for most emerging markets, event-driven, and long/short hedge fund portfolios once we account for liquidity risk. Moreover, we show that the equity market-neutral and long/short hedge fund portfolios' "alphas" also entail rents for their service as liquidity providers. These results hold under various robustness tests.
\end{abstract}

\section{Introduction}

Do hedge fund managers deliver superior performance? Given that hedge funds typically charge high fixed and performance fees, it is important to understand whether their risk-adjusted performance justifies these fees. Judging by the tremendous growth of the assets managed by hedge funds since the late 1990s, investors appear to believe that hedge funds deliver alphas (net of fees) exceeding those of traditional actively managed portfolios.

In an important advance in the risk-adjusted performance literature, Avramov and Wermers (2006) develop a higher power estimate of the performance of portfolios of mutual funds. The increased power relies on three assumptions of predictability, in i) managerial skills, ii) fund risk loadings, and iii) benchmark returns. Their estimation method involves two steps: i) the formation of optimal

*Gibson Brandon, rajna.gibson@unige.ch, University of Geneva, Unimail, 40 Bd du Pont d'Arve, 1211 Geneva 4, Switzerland, and Swiss Finance Institute; Wang, wungsungtao@yahoo.com, University of Zurich, Plattenstrasse 30, 8032 Zurich, Switzerland, and Swiss Finance Institute. We thank Georgios Gatopoulos, Olivier Scaillet, Richard Stehle, René Stulz, and seminar participants at the 2010 Funds of Hedge Funds Conference at the Zurich University of Applied Sciences, the 2009 Swiss Society for Financial Market Research Conference in Geneva, the 2008 Swiss Doctoral Workshop in Finance in Gerzensee, and the University of Zurich for valuable comments. We are particularly grateful to Stephen Brown (the editor) and Bing Liang (the referee) for their constructive comments. We gratefully acknowledge the financial support by the National Center of Competence in Research "Financial Valuation and Risk Management" (NCCR-FINRISK). All errors are our responsibility. 
portfolios using a Bayesian method to incorporate one or more of the predictability assumptions, and ii) the estimation of portfolio performance using a standard risk adjustment method. Avramov, Kosowski, Naik, and Teo (2007), (2011) employ the same method to estimate the performance for a large sample of hedge funds and conclude that some subgroups of hedge funds exhibit superior performance. In addition, they provide evidence that predictability in managerial skills is the major source of their superior performance.

Liquidity usually refers to both the time and the costs associated with the transformation of a given asset position into cash and vice versa. Typically, most continuous-time arbitrage or equilibrium asset pricing models assume that the cost and time required to transfer financial wealth into cash is zero. In practice, however, during financial crises (e.g., Asia 1997, Long-Term Capital Management (LTCM) 1998, and Subprime 2008) liquidity declines precipitously and can even temporarily dry out. Investors respond by aggressively bidding for the safest (i.e., most liquid) securities, which in turn raises their prices relative to less liquid securities. If liquidity for an entire financial market (i.e., systematic liquidity) evolves randomly, an asset's return that covaries more with systematic liquidity would yield a liquidity risk premium to compensate for an event in which the asset falls in price along with the ability to liquidate it. This conjecture is consistent with the evidence that systematic liquidity risk is priced in equity markets (Pastor and Stambaugh (2003), Gibson and Mougeot (2004)).

We conjecture that the predictable managerial skill-based alphas estimated by Avramov et al. (2007), (2011) may to some extent be attributed to the omission of a systematic liquidity risk factor in their performance evaluation framework. We follow the portfolio construction method used in Avramov et al. to test this conjecture. First, we form optimal hedge fund portfolios using their Bayesian method to incorporate the three predictability assumptions (in managerial skills, in fund risk loadings, and in benchmark returns). Second, we estimate portfolio performance using the Hasanhodzic and Lo (2007) model, augmented by a systematic liquidity risk factor constructed from the Pastor and Stambaugh (2003) liquidity measure. Finally, we examine to what extent the supply of liquidity by certain hedge funds in tight liquidity situations may explain their residual alphas (after accounting for systematic liquidity risk) in that these funds may also earn net rents from acting as liquidity providers. ${ }^{1}$

Our empirical results show that, for most equity hedge fund styles-based portfolios, the liquidity risk factor betas are significantly positive and economically relevant. This statement is particularly true for the emerging markets, eventdriven, and long/short equity hedge fund portfolios. We observe that, for $30 \%$ of the equity hedge fund portfolios, the estimated alphas are no longer significant at the $5 \%$ level, after accounting for systematic liquidity risk. Moreover, for the emerging markets funds, the significant outperformance of the predictable managerial skills-based portfolios over similar portfolios ignoring managerial skills effectively disappears once liquidity risk is accounted for. A similar but somewhat

\footnotetext{
${ }^{1}$ We are very grateful to Stephen Brown (the editor) for suggesting that hedge funds may also be earning liquidity rents that are distinct from a mere compensation for bearing systematic liquidity risk. This hypothesis is further explored at the end of Section V.
} 
less pronounced effect of liquidity risk on the event-driven style-based portfolios is also observed. Yet, two specific hedge fund portfolio classes still yield significant superior performance, even after accounting for systematic liquidity risk; these are the equity market-neutral and multistrategy fund portfolios. We finally provide indirect evidence that the equity market-neutral and long/short equity hedge fund styles-based portfolios earn liquidity provisioning rents that can explain part of their residual alphas (after accounting for liquidity risk). This finding suggests that these hedge funds are also compensated for providing market liquidity when it is scarce.

These empirical results are robust to: i) the choice of an alternative performance evaluation model (the Fung and Hsieh (2004) seven-factor (FH7) model); ii) the choice of an alternative liquidity risk proxy constructed from the Amihud (2002) liquidity measure; iii) the winsorization of hedge funds' returns; and iv) the exclusion of the impact of the recent financial crises.

We believe that these empirical results have a wide range of practical implications. First, they suggest that predictability in managerial skills is generally not sufficient to generate a "pure" and economically significant alpha for most equity hedge fund investment strategies. Second, systematic liquidity risk plays an important role, and a nonnegligible fraction of equity hedge funds' performance documented in previous studies is actually a compensation for their systematic liquidity risk exposures. Third, the residual and entire performance, respectively, documented for the equity market-neutral and long/short equity hedge funds may be associated with rents that these hedge funds earn from acting as liquidity suppliers in tight funding situations. Thus, systematic liquidity risk matters significantly and ought to be considered in the performance evaluation of most equity hedge fund investment strategies. In addition, for the equity market-neutral and long/short equity hedge funds, there is room for further research in order to understand their additional compensation as liquidity providers and to assess whether it is commensurate with the net trading benefits that they provide to other market participants in periods when market liquidity is scarce.

The organization of this article is as follows: Section II briefly surveys the literature. Section III explains the theoretical framework used in this article to form hedge fund portfolios, to construct the liquidity risk factor and, finally, to estimate the performance of hedge fund portfolios. Section IV describes the data. Empirical results are analyzed in Section V. Section VI provides the main conclusions.

\section{Literature Review}

The evaluation of hedge funds' performance is a widely studied yet still unresolved research issue in finance.

Brown, Goetzmann, and Ibbotson (1999) examine the performance of offshore hedge funds during the period from 1989 to 1995 using an annual database that includes both live and defunct hedge funds. They find that 9 out of 10 hedge fund strategies generate positive alphas. Relying on two excess return measures (i.e., alphas and appraisal ratios) over different time periods, Agarwal and Naik (2000) find evidence of short-term persistence (at the quarterly horizon). With a 
return-smoothing model, Getmansky, Lo, and Makarov (2004), however, show that the performance persistence documented by Agarwal and Naik (2000) and other papers can be simply traced to illiquidity-induced serial correlation in hedge fund returns.

Fung and Hsieh (1997) argue that hedge funds employ dynamic trading strategies that have option-like payoffs and propose a factor analysis method to extract five style factors from hedge funds' returns. In order to capture the option-like payoffs of certain dynamic trading strategies, Fung and Hsieh (2001) further propose to design and apply option-based "style factors" (in the form of portfolios replicating lookback straddles) to capture the time-series properties of trend-following strategies. Similarly, Agarwal and Naik (2004) propose to use the returns of buy-and-hold option holdings in at- and out-of-the-money options to measure the performance of hedge funds in a stepwise regression framework.

Kosowski, Naik, and Teo (2007) claim that hedge fund alphas could not be explained by luck or sample variability and that performance persists at annual horizons. They develop a powerful bootstrap and Bayesian procedure to improve on the small samples of hedge fund returns. They find a 5.5\%/year increase in the estimated alpha from the bottom to the top decile. In a paper that motivated the current study, Avramov et al. (2007), (2011) evaluate the performance of optimal hedge fund portfolios while assuming that three sources of predictability characterize hedge fund returns (predictability in fund risk loadings, in benchmark returns, and in managerial skills). They find significantly higher estimated alphas $(3 \%-5 \%)$ when they account for predictability in managerial skills.

As for systematic liquidity risk that we introduce into the hedge fund performance evaluation framework, its role in asset pricing has been intensively investigated in the finance literature. ${ }^{2}$ It is worth mentioning that systematic liquidity risk as considered in this article is distinct from the concepts of illiquidity examined in Getmansky et al. (2004) and in Aragon (2007). Indeed, we focus on liquidity risk stemming from the fact that equity hedge fund returns may covary with a marketwide systematic liquidity risk factor. The previous authors focus primarily on illiquidity as a cost factor that induces serial correlation in individual hedge fund returns and that may also provide an explanation for their higher expected returns.

Sadka (2010) is closely related to our paper but focuses on whether systematic liquidity risk is priced in the cross section of hedge fund expected returns. Sadka (2010) shows that the high-liquidity risk exposure hedge fund portfolio (top decile) has a statistically significant 6\% higher annual return, on average, than the low-liquidity risk exposure hedge fund portfolio (bottom decile) during 1994-2008. In contrast, Avramov et al. (2007), (2011) assume that an individual hedge fund return process is generated by a single equity risk factor that is, in various ways and to some degree, predictable (alpha, beta, and return). They exploit this predictability to obtain hedge fund portfolios that deliver significantly

\footnotetext{
${ }^{2}$ See, for example, Amihud (2002), Pastor and Stambaugh (2003), Acharya and Pedersen (2005), and Sadka (2006), etc.
} 
positive alphas (relative to the FH7 (2004) benchmark). Sadka (2010) raises the possibility that the alphas in Avramov et al. may be systematic liquidity risk premia. On the other hand, Avramov et al. predict individual hedge fund alpha, beta, and return with variables unrelated to liquidity. We settle the issue. For $30 \%$ of the equity hedge fund portfolios considered in our study, the estimated alphas are reduced to insignificant levels when evaluated with the Hasanhodzic and Lo (2007) model plus a systematic liquidity risk factor, and for $88.5 \%$ of the portfolios, the reduction in alphas is statistically significant at the $5 \%$ significance level.

Finally, a recent paper by Cao, Chen, Liang, and Lo (2013) is very much in the spirit of the hedge fund timing literature examining market return, volatility, and liquidity timing. Whereas Avramov et al. (2007), (2011) exploit the predictability of the return process for each individual hedge fund to form optimal hedge fund portfolios that outperform the FH7 (2004) benchmark, the former show that many hedge funds exploit their ability to time (i.e., predict) liquidity to decrease (increase) their single equity factor exposure as liquidity decreases (increases). Furthermore, while Avramov et al. provide direct evidence of the predictability of the hedge fund return process, Cao et al. provide indirect evidence that hedge fund managers can predict liquidity. The top decile of liquidity-timing hedge funds have alphas as much as $9.5 \%$ per year above the lowest decile of liquidity timers. Whether some or all of Cao et al.'s alphas represent a systematic liquidity risk premium is an interesting empirical question left for further research.

\section{The Hedge Fund Portfolio Allocation Model}

Our approach to form optimal hedge fund portfolios follows Avramov et al. (2007), (2011). Following these authors, we assume that hedge funds possess managerial skills that are predictable. Hence, within such a portfolio allocation model, we can investigate whether predictability in managerial skills is really effective in so far as it allows one to incorporate highly skilled hedge fund managers in portfolios that subsequently generate higher excess returns, even after accounting for liquidity risk.

Assume that there are several types of Bayesian optimizing investors who differ from each other with respect to their views about the parameters governing the following hedge fund return-generating model:

$$
\begin{aligned}
r_{i, t} & =\alpha_{i, 0}+\alpha_{i, 1}^{\prime} z_{t-1}+\beta_{i, 0}^{\prime} f_{t}+\beta_{i, 1}^{\prime}\left(f_{t} \otimes z_{t-1}\right)+\epsilon_{i, t}, \\
f_{t} & =a_{f}+A_{f} z_{t-1}+\epsilon_{f, t} \\
z_{t} & =a_{z}+A_{z} z_{t-1}+\epsilon_{z, t}
\end{aligned}
$$

where $r_{i, t}$ is the return of hedge fund $i$ in excess of the riskless interest rate in month $t, z_{t}$ is a vector of $\mathrm{M}$ business cycle variables observed at the end of month $t, f_{t}$ is a vector of $\mathrm{K}$ zero-cost benchmarks, $\beta_{i, 0}\left(\beta_{i, 1}\right)$ is the fixed (variable) component of fund risk loadings, and $\epsilon_{i, t}$ is a fund-specific event that is assumed to be uncorrelated across hedge funds and over time and to be normally distributed 
with mean zero and variance $\psi_{i}$. The business cycle variables $z_{t}$ are modeled by a vector autoregression of order one.

The model describing hedge fund returns in equation (1) captures predictability in managerial skills $\left(\alpha_{i, 1} \neq 0\right)$, in fund risk loadings $\left(\beta_{i, 1} \neq 0\right)$, and in benchmark returns $\left(A_{f} \neq 0\right)$.

Hedge fund managers' skills are captured by the term $\alpha_{i, 0}+\alpha_{i, 1}^{\prime} z_{t-1}$ that is composed of the fixed component $\alpha_{i, 0}$ and the predictable component $\alpha_{i, 1}^{\prime} z_{t-1}$. Note that the predictability of managerial skills is explained by public information rather than the private information possessed by hedge fund managers. This statement is consistent with the fact that the private information of the manager is correlated with the chosen business cycle variables that capture publicly available information.

\section{A. Investor Types}

Following Avramov et al. (2007), (2011), we consider three specific types of hypothetical Bayesian investors who hold different views about the existence of managerial skills: ${ }^{3}$

The first type of investor is called the dogmatist, who rules out the existence of managerial skills. The dogmatist is further divided into three subtypes: i) subtype (ND) rules out any possible predictability; ii) subtype (PD1) is a predictability dogmatist, but he only believes in the predictability of fund risk loadings; and iii) subtype (PD2) believes in the predictability of both fund risk loadings and benchmark returns.

The second type of investor is agnostic about the existence and level of managerial skills. For the agnostic investor, prior beliefs are noninformative, and managerial skills are completely determined by the observed data. Assume that there are two subtypes of agnostic investors: The first subtype of agnostic investor (PA1) believes that only managerial skills are predictable, while the second subtype (PA2) believes that managerial skills, fund risk loadings, and benchmark returns are all predictable. ${ }^{4}$

The skeptic, as the third type of investor, is an investor who believes in the existence of managerial skills, but his beliefs are bounded. As in the agnostic case, we also consider two subtypes of skeptic investors: The first subtype (PS1) believes that only managerial skills are predictable, and the second subtype (PS2) believes that hedge fund allocation decisions can be improved by exploiting the business cycle variables that potentially predict managerial skills, fund risk loadings, and benchmark returns.

\footnotetext{
${ }^{3}$ See Avramov and Wermers (2006) for a detailed description of the investor types used in this article.

${ }^{4}$ But, unlike Avramov et al. (2007), (2011), we do not consider three other types of agnostic investors who admit the existence of managerial skills but deny their predictability. Avramov and Wermers (2006) and Avramov et al. show that predictability in managerial skills is the main source of outperformance and that the investors who admit the existence of managerial skills but deny their predictability do not outperform other investors who rule out managerial skills. The same arguments apply to the types of skeptic investors.
} 


\section{B. Optimal Portfolio Formation}

At each time $t$, there exist $N_{t}$ hedge funds defining the investment opportunity set, with $N_{t}$ varying over time. We follow Avramov et al. (2007), (2011) in that each investor forms his portfolio by maximizing the conditional expected value of a quadratic utility function,

$$
U\left(W_{t}, R_{p, t+1}, a_{t}, b_{t}\right)=a_{t}+W_{t} R_{p, t+1}-\frac{b_{t}}{2} W_{t}^{2} R_{p, t+1}^{2}
$$

where $W_{t}$ denotes the time $t$ invested wealth, $b_{t}$ reflects the absolute risk aversion parameter, $R_{p, t+1}$ is the realized excess return on the optimal portfolio $p$ computed as $R_{p, t+1}=1+r_{f t}+w_{t}^{\prime} r_{t+1}$ with $r_{f t}$ being the riskless interest rate, $r_{t+1}$ denoting the vector of hedge fund excess returns, and $w_{t}$ denoting the vector of the optimal hedge fund allocations. Taking conditional expectations on both sides of equation (2) yields the following optimization problem:

$$
w_{t}^{*}=\underset{w_{t} \geq 0}{\operatorname{argmax}}\left\{w_{t}^{\prime} \mu_{t}-\frac{1}{2\left(1 / \gamma_{t}-r_{f t}\right)} w_{t}^{\prime} \Lambda_{t}^{-1} w_{t}\right\},
$$

where $\gamma_{t}=\left(b_{t} W_{t}\right) /\left(1-b_{t} W_{t}\right)$ is the relative risk aversion parameter, $\Lambda_{t}=$ $\left[\Sigma_{t}+\mu_{t} \mu_{t}^{\prime}\right]^{-1}$, with $\mu_{t}$ and $\Sigma_{t}$ denoting, respectively, the mean vector and the variance-covariance matrix of hedge fund excess returns. The possibility of leveraging and short selling is excluded when we form the optimal hedge fund portfolios.

Investors update their prior beliefs once they obtain new information, and the posterior densities of the parameters are obtained by combining the likelihood functions and the prior distributions. With such densities, investors can calculate the Bayesian predictive distribution of hedge fund returns $r_{t+1}$, from which the mean vector $\mu_{t}$ and the variance-covariance matrix $\Sigma_{t}$ of hedge fund excess returns are derived.

We use the excess return on the value-weighted Standard \& Poor's (S\&P) 500 index as the benchmark factor to derive the optimal portfolios for the seven types of investors defined as above. This allows us to compare our results with those previously obtained by Avramov et al. (2007), (2011).

\section{Performance Evaluation Model}

We use the Hasanhodzic and Lo (2007) six-factor model and its extended version to evaluate the performance of the optimal portfolios of the seven types of investors defined as above. This choice is motivated by the fact that this model accounts for a broad cross section of risk exposures for a typical hedge fund and that it is widely accepted in the recent hedge fund literature. The six risk factors are: i) the excess return on the S\&P 500 index (SP500); ii) the excess return on the U.S. Dollar Index (USDX); iii) the excess return on the Goldman Sachs Commodity Index (GSCI); iv) the excess return on the Lehman Corporate AA Intermediate Bond Index (YIELD); v) the return spread on the Lehman BAA 
Corporate Bond Index and the Lehman Treasury Index (SPREAD); and vi) the volatility risk factor (VOLA). ${ }^{5}$

We regress each portfolio's monthly excess returns on these six factors:

$$
\begin{aligned}
r_{i, t}= & \alpha_{i}+\beta_{i, 1} \operatorname{SP} 00_{t}+\beta_{i, 2} \operatorname{USDX}_{t}+\beta_{i, 3} \mathrm{GSCI}_{t} \\
& +\beta_{i, 4} \mathrm{YIELD}_{t}+\beta_{i, 5} \operatorname{SPREAD}_{t}+\beta_{i, 6} \mathrm{VOLA}_{t}+v_{i, t} .
\end{aligned}
$$

We also use the Fung and Hsieh (2004) model with and without a liquidity risk factor to evaluate the performance of the optimal hedge fund portfolios in Section V.D.

\section{Liquidity Risk Factors}

In what follows, we discuss the construction of liquidity risk factors that will be added to the performance evaluation model described in the previous subsection in order to examine whether a liquidity risk factor can explain the previously documented abnormal performance of hedge funds even after accounting for the existence of predictable managerial skills. The first liquidity risk factor is constructed from the liquidity measure proposed by Pastor and Stambaugh (2003). In their paper, the illiquidity of stock $i$ in year $y$ is defined as the ordinary least squares estimate of $\gamma_{i, t}$ in the regression

$$
r_{i, d+1, y}^{e}=\theta_{i, y}+\phi_{i, y} r_{i, d, y}+\gamma_{i, y} \operatorname{sign}\left(r_{i, d, y}^{e}\right) v_{i, d, y}+\epsilon_{i, d+1, y},
$$

where $r_{i, d, y}$ is the return of stock $i$ on day $d$ in year $y ; r_{i, d, y}^{e}=r_{i, d, y}-r_{m, d, y}, r_{m, d, y}$ being the return on the value-weighted Center for Research in Security Prices (CRSP) index on day $d$ in year $y$; and $v_{i, d, y}$ is the trading volume (in millions of U.S. dollars) for stock $i$ on day $d$ in year $y$.

This liquidity measure $\gamma_{i, t}$ focuses on an aspect of illiquidity associated with temporary price fluctuations induced by the order flow. Essentially, greater illiquidity corresponds to stronger volume-related return reversals, and in this respect this measure follows the same line of reasoning as the model and the empirical evidence presented by Campbell, Grossman, and Wang (1993). Here, $\gamma_{i, y}$ is usually negative and larger in absolute level when liquidity is lower.

Stocks are ranked into 25 portfolios $p=1,2, \ldots, 25$ according to their annual illiquidity measures at the end of the previous year. The first portfolio is composed of the most liquid stocks, while the least liquid stocks are in the last portfolio. For each portfolio $p$, we calculate its return in month $t$ as

$$
r_{t}^{p}=\sum_{i \in p} w_{t}^{i p} r_{t}^{i}
$$

\footnotetext{
${ }^{5}$ We use the data on the S\&P 500 index constituent stocks to construct the VOLA. At the beginning of each year from 1996 to 2006, we regress the excess returns of each of the S\&P 500 index constituent stocks during the prior 24 months on the value-weighted market excess returns and the Chicago Board Options Exchange (CBOE) volatility indices, and we rank stocks into 20 portfolios according to their loadings with respect to the volatility index. The VOLA is then calculated as the return difference between the portfolios composed of the stocks with the highest and lowest sensitivities to the CBOE volatility index.
} 
where $w_{t}^{i p}$ are either equal- or value-based weights, depending on the specification. In the following, we only present the empirical results estimated from equal-weighted returns; the results estimated from value-weighted returns are quantitatively similar.

The liquidity risk factor denoted by $\mathrm{LIQ}^{\mathrm{PS}}$ is defined as the return on the least liquid portfolio minus the return on the most liquid portfolio, and its value in month $t$ is

$$
\mathrm{LIQ}_{t}^{\mathrm{PS}}=r_{t}^{25}-r_{t}^{1}
$$

By definition, this factor can be interpreted as the return that investors are willing to give up for holding more liquid stocks.

The liquidity risk factor $\mathrm{LIQ}^{\mathrm{PS}}$ then can be incorporated into equation (4) to study the effect of liquidity risk on the performance of the optimal hedge fund portfolios formed according to the portfolio optimization scheme described in Section III.B.

In order to study the robustness of the results, we also evaluate the performance of the optimal hedge fund portfolios using another liquidity risk factor, denoted by $\mathrm{LIQ}^{\mathrm{AMH}}$, which is constructed from the liquidity measure proposed by Amihud (2002). The illiquidity of stock $i$ is alternatively defined as the ratio of its daily absolute return to the daily trading volume (in millions of U.S. dollars). More precisely, this measure equals $\left|R_{i y d}\right| / \mathrm{VOL}_{i y d}$, where $R_{i y d}$ is the return on stock $i$ on day $d$ of year $y$, and $\mathrm{VOL}_{i y d}$ is the respective daily trading volume. This measure follows Kyle's (1985) concept of illiquidity as the response of price to order flow.

The annual illiquidity of stock $i$ in year $y$ is equal to the sum of the daily illiquidities in this year divided by the number of available trading days:

$$
\mathrm{ILLIQ}_{i y}=\frac{1}{D_{i y}} \sum_{t=1}^{D_{i y}}\left|R_{i y d}\right| / \mathrm{VOL}_{i y d},
$$

where $D_{i y}$ is the number of trading days for which trading data are available for stock $i$ in year $y$. The Amihud (2002) liquidity risk factor LIQ ${ }^{\mathrm{AMH}}$ can be constructed following the procedure as described above for the construction of the $\mathrm{LIQ}^{\mathrm{PS}}$ factor.

\section{Data}

The hedge fund data used in this article are provided by the Lipper TASS database. TASS divides hedge funds into 11 categories designed to reflect the primary hedge fund investment styles. This study only focuses on equity hedge fund styles, since the liquidity risk factors used in this article are constructed with equity data and are thus expected to better explain the performance of equity hedge funds. Precisely, we rely on the emerging markets, equity market-neutral, event-driven, long/short equity hedge, and multistrategy hedge fund styles. ${ }^{6}$

\footnotetext{
${ }^{6}$ In the descriptive statistics section, we also present the data for the dedicated short bias hedge fund style. But, due to the limited number of hedge funds in this category (only 18 of them alive before
} 
Although the TASS database dates back to Feb. 1977, we start our study in Jan. 1994 to capture the date when TASS started to report the data for "graveyard" hedge funds in order to avoid the well-documented survivorship bias. This study extends from Jan. 1994 to Dec. 2006. ${ }^{7}$ Another well-known bias associated with hedge fund returns is the backfilling bias: The database vendor may backfill new hedge funds' performance when they are added instead of only including their returns going forward. This bias also shifts hedge fund returns upward. To mitigate the impact of the backfilling bias, we exclude the first 12-month return data for each hedge fund.

Hedge funds were excluded when they: i) did not report net-of-fees returns; ii) reported returns in currencies other than the U.S. dollar; iii) reported returns less frequently than monthly; and iv) had fewer than 24 monthly returns.

Table 1 presents summary statistics for equity hedge funds in the sample: Panel A for live hedge funds, and Panel B for both live and defunct hedge funds. About $64 \%$ of hedge funds are left after the filtration of the data. The results in Panels A and B show that the average annualized returns and Sharpe ratios are higher for live hedge funds within all but dedicated short bias hedge fund styles; this result strongly supports the existence of the survivorship bias. Table 1 also documents the positive first-order autocorrelation of hedge fund returns, particularly within the emerging markets, event-driven, and multistrategy hedge fund

\section{TABLE 1}

\section{Summary Statistics of Hedge Fund Returns}

\begin{tabular}{|c|c|c|c|c|c|c|c|c|c|}
\hline \multirow[b]{2}{*}{ Fund Style } & \multirow[b]{2}{*}{$\underline{\text { Sample Size }}$} & \multicolumn{2}{|c|}{$\begin{array}{l}\text { Annualized } \\
\text { Mean }(\%)\end{array}$} & \multicolumn{2}{|c|}{$\begin{array}{l}\text { Annualized } \\
\text { STDV }(\%)\end{array}$} & \multicolumn{2}{|c|}{$\begin{array}{c}\text { Annualized } \\
\text { Sharpe Ratio }\end{array}$} & \multicolumn{2}{|c|}{$\rho_{1}(\%)$} \\
\hline & & Mean & $\underline{\text { STDV }}$ & Mean & $\underline{\text { STDV }}$ & Mean & $\underline{\text { STDV }}$ & Mean & $\underline{\text { STDV }}$ \\
\hline \multicolumn{10}{|l|}{ Panel A. Live Hedge Funds } \\
\hline $\begin{array}{l}\text { Dedicated short bias } \\
\text { Emerging markets } \\
\text { Equity market-neutral } \\
\text { Event-driven } \\
\text { Long/short equity hedge } \\
\text { Multistrategy }\end{array}$ & $\begin{array}{rr}16 & (18) \\
164 & (229) \\
142 & (212) \\
271 & (337) \\
798 & (1,189) \\
121 & (176)\end{array}$ & $\begin{array}{r}-5.28 \\
21.66 \\
8.91 \\
13.98 \\
14.98 \\
13.17\end{array}$ & $\begin{array}{r}6.52 \\
21.37 \\
6.40 \\
12.17 \\
15.65 \\
9.57\end{array}$ & $\begin{array}{r}19.12 \\
15.21 \\
6.38 \\
7.10 \\
12.79 \\
7.50\end{array}$ & $\begin{array}{r}10.73 \\
11.95 \\
4.88 \\
7.59 \\
7.85 \\
8.67\end{array}$ & $\begin{array}{r}-0.84 \\
1.64 \\
1.12 \\
2.41 \\
0.99 \\
2.47\end{array}$ & $\begin{array}{l}1.46 \\
2.45 \\
1.50 \\
4.58 \\
1.06 \\
4.12\end{array}$ & $\begin{array}{r}0.00 \\
11.38 \\
0.19 \\
17.77 \\
6.81 \\
12.67\end{array}$ & $\begin{array}{l}24.29 \\
20.17 \\
26.02 \\
21.58 \\
20.68 \\
25.44\end{array}$ \\
\hline \multicolumn{10}{|c|}{ Panel B. Live and Defunct Hedge Funds } \\
\hline $\begin{array}{l}\text { Dedicated short bias } \\
\text { Emerging markets } \\
\text { Equity market-neutral } \\
\text { Event-driven } \\
\text { Long/short equity hedge } \\
\text { Multistrategy }\end{array}$ & $\begin{array}{rr}31 & (38) \\
279 & (406) \\
255 & (441) \\
453 & (601) \\
1,444 & (2,330) \\
167 & (289)\end{array}$ & $\begin{array}{r}-2.95 \\
9.88 \\
6.83 \\
11.22 \\
10.16 \\
11.97\end{array}$ & $\begin{array}{r}8.92 \\
18.74 \\
8.23 \\
10.42 \\
13.70 \\
13.77\end{array}$ & $\begin{array}{r}21.57 \\
20.70 \\
7.38 \\
8.23 \\
15.74 \\
9.51\end{array}$ & $\begin{array}{r}12.17 \\
15.32 \\
5.14 \\
9.27 \\
11.79 \\
10.43\end{array}$ & $\begin{array}{r}-0.23 \\
0.61 \\
0.65 \\
1.47 \\
0.63 \\
1.46\end{array}$ & $\begin{array}{l}0.49 \\
1.04 \\
1.10 \\
2.71 \\
0.83 \\
1.90\end{array}$ & $\begin{array}{r}7.98 \\
14.32 \\
2.84 \\
18.94 \\
8.41 \\
11.97\end{array}$ & $\begin{array}{l}10.59 \\
16.36 \\
22.16 \\
18.93 \\
17.05 \\
23.86\end{array}$ \\
\hline
\end{tabular}

the filtration of the data, see Panel A of Table 1), this category was excluded when forming the optimal hedge fund portfolios.

${ }^{7}$ The sample used by Avramov et al. (2007), (2011) consists of hedge funds in the TASS, HFR, CISDM, and MSCI databases over the period from Jan. 1990 to Dec. 2002. 
styles. According to Getmansky et al. (2004), the positive first-order autocorrelation of a hedge fund's returns can be used as a proxy for its illiquidity level arising from the lack of liquidity of its assets and/or from the return smoothing performed by its managers. This measure does not necessarily map into the systematic liquidity risk exposure of a given hedge fund portfolio as measured by its liquidity beta, which reflects its exposure to (and covariation with) stock marketwide liquidity shocks (long/short equity hedge and multistrategy hedge fund styles provide counterexamples to this mapping).

Stock daily return and volume data used to construct the liquidity risk factors $\mathrm{LIQ}^{\mathrm{PS}}$ and $\mathrm{LIQ}^{\mathrm{AMH}}$ are downloaded from CRSP. We only use common stocks traded on the NYSE and the AMEX, since the trading volume of stocks traded on the NASDAQ include interdealer data that result from a different trading mechanism. In year $y$, a stock is considered when it satisfies the following criteria: i) the stock was listed at the end of year $y-1$; ii) the stock price at the end of year $y-1$ was higher than $\$ 5$ and lower than $\$ 1,000$; and iii) the stock had return and volume data for over 100 days in year $y-1$.

The monthly Pastor and Stambaugh (2003) and Amihud (2002) market liquidity series during the period between Jan. 1996 and Dec. 2006 are plotted in Graphs A and B of Figure 1, respectively. Each month's observation is obtained by averaging individual stock liquidity measures for the month and then multiplying them by $m_{t} / m_{1}$, where $m_{t}$ is the total dollar value at the end of month $t-1$ of the stocks included in the average in month $t$, and month 1 corresponds to

\section{FIGURE 1}

\section{Market Liquidity}

Graph A of Figure 1 plots the monthly Pastor and Stambaugh (2003) market liquidity series, while the monthly Amihud (2002) market liquidity series is plotted in Graph B, both during the period between Jan. 1996 and Dec. 2006. Each month's observation is obtained by averaging individual stock liquidity measures for the month and then multiplying them by $m_{t} / m_{1}$, where $m_{t}$ is the total dollar value at the end of month $t-1$ of the stocks included in the average in month $t$, and month 1 corresponds to Aug. 1962.

Graph A. Pastor and Stambaugh

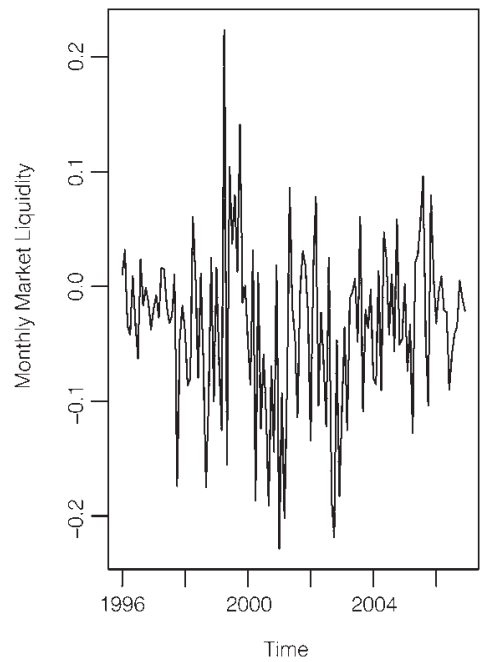

Graph B. Amihud

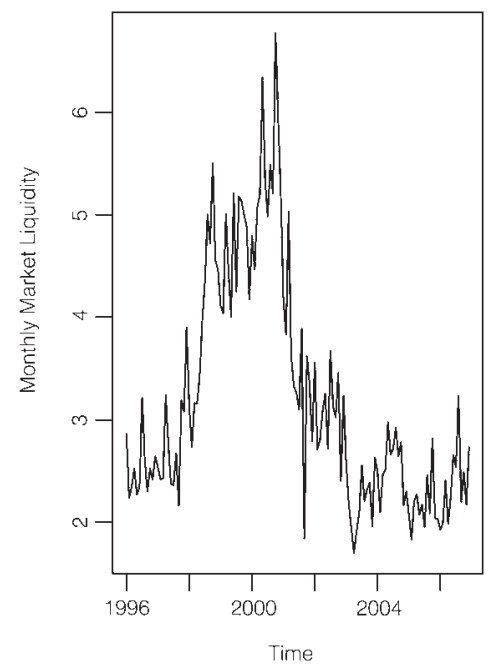


Aug. 1962. The multiplier $m_{t} / m_{1}$ reflects the cost of a trade whose size is commensurate with the overall size of the stock market. The series in Graphs A and B show that liquidity is significantly lower and the return for liquidity thus significantly higher during the periods characterized by liquidity crises such as: JuneOct. 1998 (Russian government bond default and LTCM crisis) and 2000-2001 (dot.com bubble crash). This is particularly striking from looking at the evolution of the Amihud (2002) liquidity measure in Graph B; the latter measure has further been very high until the beginning of 2003, a date corresponding with the gradual introduction of the Autoquote system by the NYSE (see Jylha, Rinne, and Suominen (2011)).

The correlation between the market risk factor S\&P 500 and the liquidity risk factors $\mathrm{LIQ}^{\mathrm{PS}}$ and $\mathrm{LIQ}^{\mathrm{AMH}}$ is high (in absolute terms) and negative: -0.609 and -0.527 , suggesting that investors will require higher returns for less liquid securities when the market is trending down. This result is consistent with the concept of "flight to quality" during market downturn periods. The correlation between the two liquidity risk factors is high at 0.892; thus, the Pastor and Stambaugh (2003) and Amihud (2002) liquidity measures seem to capture a similar trend in liquidity risk over time.

\section{Empirical Results}

This section presents the out-of-sample performance results for the optimal hedge fund portfolios from the perspective of the seven types of investors defined in Section III. At the end of each year from 1995 to 2005, the portfolio for each investor is derived using the previous 24-month information. Due to the fact that lockup provisions and redemption notice periods are common in the hedge fund industry, it takes time for investors to withdraw money from hedge funds, and we thus rebalance portfolios only once every 12 months. ${ }^{8}$

We follow Avramov et al.'s (2007), (2011) selection of four business cycle variables: namely, the Treasury yield; the default spread, defined as the yield difference between Moody's Baa-rated and Aaa-rated bonds; the term spread, defined as the yield difference between T-bonds with more than 10 years to maturity and the 3-month T-bill rate; and the contemporaneous monthly CBOE volatility index. In the finance literature, the first three variables are often used to predict stock returns. To the extent that many hedge fund managers engage in volatility bets, the fourth variable should allow investors to predict hedge fund managers' ability of timing volatility.

\section{A. Descriptive Statistics}

Table 2 gives summary statistics for the seven optimal portfolios' actual and bootstrapped returns reported by hedge fund styles. ${ }^{9}$

\footnotetext{
${ }^{8}$ Avramov et al. (2007), (2011) show that reforming portfolios over a shorter horizon does not change the relative performance of different portfolio strategies.

${ }^{9}$ See the Appendix for a detailed description of the bootstrap method used.
} 
TABLE 2

Summary Statistics of Portfolios' Returns by Hedge Fund Styles

Table 2 reports, within each of the equity hedge fund styles of emerging markets, equity market-neutral, event-driven, long/short equity hedge, and multistrategy, summary statistics during the period between 1996 and 2006 for the returns of the portfolios that are optimal from the perspective of the seven types of investors as described in the context: mean, bootstrapped mean (b-Mean), minimum (Min), maximum (Max), standard deviation (STDV), annualized Sharpe ratio (SH_R), bootstrapped annualized Sharpe ratio (b-SH_R), skewness (SKEW), and kurtosis (KURT). The optimal portfolios are formed by assuming that investors use the benchmark factor defined as the return on the value-weighted S\&P 500 index to form expectations about future moments for asset allocation. Investors rebalance their portfolios every 12 months. Within each hedge fund style, the bolded number in the b-Mean (b-SH_R) column is the highest mean return (Sharpe ratio) that is significantly, at the $5 \%$ level, higher than the other mean returns (Sharpe ratios).

Portfolio Mean b-Mean Min Max

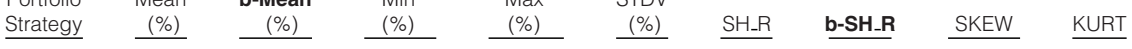

Panel A. Emerging Markets Fund Style

$\begin{array}{lrllllllrr}\text { ND } & 0.832 & 0.727 & -47.21 & 22.54 & 7.83 & 0.232 & 0.231 & -1.814 & 13.55 \\ \text { PD1 } & 1.093 & 1.010 & -34.75 & 16.57 & 5.31 & 0.511 & 0.529 & -2.405 & 18.05 \\ \text { PD2 } & 0.959 & 0.915 & -32.44 & 13.44 & 4.86 & 0.463 & 0.508 & -2.623 & 19.20 \\ \text { PS1 } & 2.104 & \mathbf{1 . 8 9 0} & -42.87 & 34.94 & 9.27 & 0.671 & 0.613 & -0.170 & 7.77 \\ \text { PS2 } & 0.777 & 0.530 & -22.34 & 22.25 & 7.01 & 0.231 & 0.123 & -0.206 & 4.09 \\ \text { PA1 } & 1.879 & 1.664 & -14.11 & 26.08 & 7.59 & 0.716 & 0.624 & -0.801 & 4.12 \\ \text { PA2 } & 1.978 & 1.691 & -39.90 & 24.15 & 7.34 & 0.787 & \mathbf{0 . 7 1 7} & -1.045 & 10.72\end{array}$

Panel B. Equity Market-Neutral Fund Style

\begin{tabular}{|c|c|c|c|c|c|c|c|c|c|}
\hline ND & 0.718 & 0.605 & -7.33 & 13.69 & 3.62 & 0.394 & 0.287 & 0.698 & 4.74 \\
\hline PD1 & 1.050 & 1.047 & -5.43 & 8.91 & 2.34 & 1.109 & 1.108 & 0.128 & 4.49 \\
\hline PD2 & 0.943 & 0.942 & -5.01 & 9.07 & 2.18 & 1.016 & 1.014 & 0.457 & 4.87 \\
\hline PS1 & 1.781 & 1.791 & -12.39 & 15.51 & 4.31 & 1.187 & 1.197 & -0.096 & 5.11 \\
\hline PS2 & 1.291 & 1.332 & -9.44 & 10.02 & 3.21 & 1.061 & 1.102 & -0.244 & 4.05 \\
\hline PA1 & 1.585 & 1.621 & -13.34 & 17.07 & 4.00 & 1.102 & 1.162 & -0.429 & 6.82 \\
\hline PA2 & 1.263 & 1.298 & -13.78 & 13.20 & 3.10 & 1.068 & 1.150 & -0.491 & 9.89 \\
\hline \multicolumn{10}{|c|}{ Panel C. Event-Driven Fund Style } \\
\hline ND & 1.087 & 1.034 & -18.85 & 14.94 & 3.79 & 0.711 & 0.683 & -0.873 & 9.07 \\
\hline PD1 & 0.834 & 0.800 & -16.25 & 8.99 & 2.87 & 0.636 & 0.652 & -1.730 & 12.41 \\
\hline PD2 & 0.763 & 0.733 & -16.21 & 8.11 & 2.76 & 0.570 & 0.599 & -2.062 & 14.06 \\
\hline PS1 & 1.374 & 1.266 & -14.15 & 12.84 & 5.07 & 0.726 & 0.671 & -0.428 & 3.54 \\
\hline PS2 & 1.166 & 1.064 & -20.00 & 16.82 & 5.35 & 0.554 & 0.511 & -0.701 & 5.89 \\
\hline PA1 & 1.385 & 1.279 & -17.11 & 18.79 & 6.42 & 0.578 & 0.529 & -0.102 & 3.88 \\
\hline PA2 & 1.604 & 1.521 & -9.41 & 12.41 & 3.89 & 1.149 & 1.087 & -0.026 & 3.32 \\
\hline \multicolumn{10}{|c|}{ Panel D. Long/Short Equity Hedge Fund Style } \\
\hline ND & 1.249 & 1.245 & -31.34 & 17.23 & 6.44 & 0.507 & 0.510 & -0.688 & 7.61 \\
\hline PD1 & 1.026 & 0.978 & -10.10 & 11.16 & 3.46 & 0.724 & 0.661 & 0.095 & 4.42 \\
\hline PD2 & 1.448 & 1.403 & -10.92 & 10.91 & 3.25 & 1.224 & 1.170 & -0.147 & 5.15 \\
\hline PS1 & 1.474 & 1.458 & -14.86 & 28.69 & 6.74 & 0.600 & 0.583 & 0.831 & 5.20 \\
\hline PS2 & 1.202 & 1.097 & -42.69 & 102.80 & 12.19 & 0.254 & 0.223 & 3.993 & 39.42 \\
\hline PA1 & 1.052 & 1.013 & -11.96 & 20.11 & 5.44 & 0.473 & 0.440 & 0.733 & 4.39 \\
\hline PA2 & 1.338 & 1.323 & -14.96 & 17.31 & 5.54 & 0.644 & 0.641 & -0.177 & 3.52 \\
\hline \multicolumn{10}{|c|}{ Panel E. Multistrategy Fund Style } \\
\hline ND & 1.222 & 1.187 & -17.63 & 13.25 & 4.47 & 0.710 & 0.681 & -0.359 & 5.27 \\
\hline PD1 & 1.407 & 1.366 & -17.63 & 11.42 & 3.33 & 1.146 & 1.144 & -1.022 & 10.57 \\
\hline PD2 & 1.361 & 1.389 & -16.01 & 10.91 & 3.40 & 1.071 & 1.159 & -0.928 & 8.48 \\
\hline PS1 & 3.222 & 3.278 & -17.63 & 61.87 & 8.14 & 1.236 & 1.292 & 2.951 & 22.57 \\
\hline PS2 & 2.290 & 2.291 & -17.63 & 51.36 & 7.07 & 0.970 & 0.976 & 2.592 & 19.79 \\
\hline PA1 & 3.133 & 3.198 & -17.63 & 83.13 & 9.79 & 0.997 & 1.055 & 4.247 & 35.40 \\
\hline PA2 & 3.220 & 3.272 & -11.65 & 101.80 & 9.72 & 1.036 & 1.255 & 7.978 & 81.71 \\
\hline
\end{tabular}

Table 2 documents that the optimal hedge fund portfolio strategies that account for predictability in managerial skills generate higher average returns than the strategies excluding managerial skills, though the difference is rather small for the long/short equity hedge fund portfolios. For instance, for the event-driven funds, the average return generated by the portfolio PA2 is $1.6 \% /$ month $(0.5 \% /$ month higher than the highest average return generated by the dogmatic strategies). Looking at the Sharpe ratios, the results are, however, mixed. For the long/short equity hedge funds, the portfolios ND, PD1, and PD2 generate 
higher Sharpe ratios, and for the equity market-neutral and multistrategy funds, the highest Sharpe ratios generated by the strategies that do and do not incorporate predictable managerial skills are close. These conclusions also apply to the bootstrapped average returns and Sharpe ratios displayed in Table 2.

The combination of higher average returns and relatively lower Sharpe ratios implies that the returns generated by the portfolios PS1, PS2, PA1, and PA2 are more volatile, which is emphasized in Table 2. One potential explanation for the more volatile returns generated by the portfolios PS1, PS2, PA1, and PA2 is the fact that the number of hedge funds in these portfolios is much lower over time. ${ }^{10}$ Hence, they are less diversified and more volatile.

Finally, the returns of the emerging markets and event-driven styles-based portfolios and of almost half of the portfolios belonging to the equity marketneutral, long/short equity hedge, and multistrategy styles display negative skewness and are left-tailed, meaning that these portfolios may suffer from infrequent but extreme losses.

\section{B. Analysis of the Optimal Portfolios' Composition}

We further analyze some characteristics of the optimal hedge fund portfolios' constituents.

The portfolio characteristics considered here include: the number of hedge funds, the age of hedge funds since their inception (in years), redemption notice periods (in days), lockup provisions (in months), and assets under management (in hundred of millions of dollars). At the end of each year from 1995 to 2005, the value of a portfolio characteristic is defined as the equal-weighted average of individual hedge funds' characteristics. The numbers in Table 3 correspond to the time-series averages of portfolio characteristics' values over the entire sample period.

On average, the portfolios excluding managerial skills are composed of more hedge funds; this feature may partially explain a phenomenon documented in Section V.A, namely, that these portfolios are less volatile as they are more diversified. Within all hedge fund styles, the time-series average numbers of hedge funds for the portfolios ND, PD1, and PD2 are at least twice as large as those for the other four portfolios. This observation is not surprising because, as implied by the hedge fund return-generating model (1), the skeptic and agnostic investors prefer to bet on the specific risks of hedge funds, while the dogmatic investors try to diversify their risk exposures.

Another interesting result recorded in Table 3 is that the portfolios accounting for managerial skills are not necessarily composed of hedge funds with more restrictive lockup provisions and redemption notice periods. Aragon (2007) uses hedge fund share restrictions like lockup provisions and redemption notice periods as transaction cost approximation and documents a positive and concave relation between share restrictions and excess returns on hedge funds. ${ }^{11}$ One

\footnotetext{
${ }^{10}$ See Table 3 in the following subsection.

${ }^{11}$ Liang (1999) was the first to document a positive relationship between average hedge fund returns and the length of their lockup period.
} 
TABLE 3

Analysis of Optimal Portfolios' Components

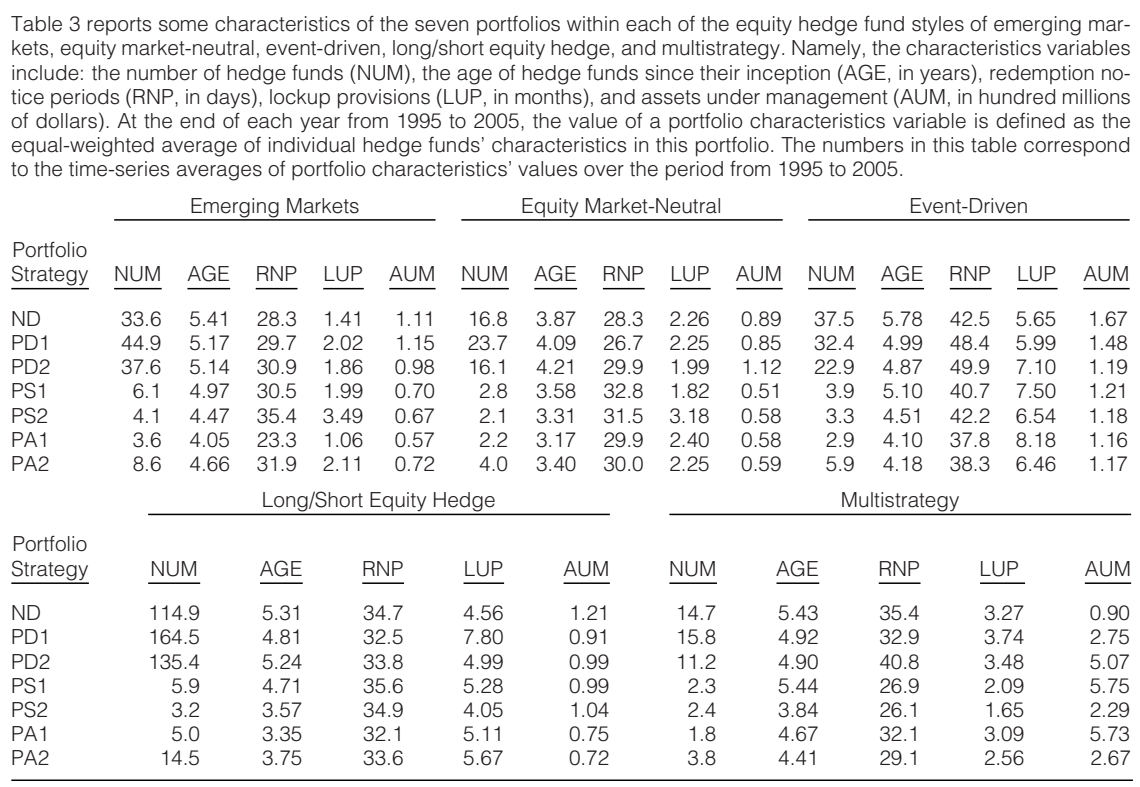

implication of these results is that our subsequent conclusions about the effect of liquidity risk on hedge fund performance are most likely not driven by hedge fund share restrictions.

Finally, hedge funds in the dogmatic portfolios generally tend to be older and to manage more assets than those contained in the skeptic and agnostic investors' portfolios.

\section{Performance Evaluation Results}

We first evaluate the out-of-sample performance of the optimal hedge fund portfolios with the Hasanhodzic and Lo (2007) model and then using the extended performance evaluation model that is obtained by including the liquidity risk factor $\mathrm{LIQ}^{\mathrm{PS}}$ in equation (4).

The evaluation results excluding the effect of liquidity risk are reported in Table 4. First, we corroborate Avramov et al.'s (2007), (2011) empirical results, since we also find that the portfolio strategies that incorporate predictability in managerial skills yield superior performance compared to the other strategies. For example, for the emerging markets funds, the alphas generated by the portfolios PS1, PA1, and PA2 are significant at the 5\% level and more than one time higher than the alphas generated by the portfolios ND, PD1, and PD2. In addition, 
for the event-driven funds, the significant alpha of portfolio PA2 is much higher than those of portfolios ND, PD1, and PD2. ${ }^{12}$

TABLE 4

Out-of-Sample Performance of Portfolio Strategies

\begin{tabular}{|c|c|c|c|c|c|c|c|c|c|}
\hline \multirow{2}{*}{$\begin{array}{l}\text { Portfolio } \\
\text { Strategy } \\
\end{array}$} & \multicolumn{3}{|c|}{ Emerging Markets } & \multicolumn{3}{|c|}{ Equity Market-Neutral } & \multicolumn{3}{|c|}{ Event-Driven } \\
\hline & $\alpha$ & $\alpha \mathrm{PS}$ & $\beta_{\mathrm{PS}}$ & $\alpha$ & $\alpha \mathrm{PS}$ & $\beta_{\mathrm{PS}}$ & $\alpha$ & $\alpha_{\mathrm{PS}}$ & $\beta_{\mathrm{PS}}$ \\
\hline ND & 0.11 & -0.49 & $0.77^{\star \star}$ & 0.29 & -0.02 & $0.40^{\star \star}$ & $0.60^{*}$ & 0.34 & $0.33^{\star *}$ \\
\hline PD1 & 0.61 & 0.22 & $0.49^{\star \star}$ & $0.81^{\star \star}$ & $0.77^{\star \star}$ & 0.05 & 0.38 & 0.11 & $0.36^{\star \star}$ \\
\hline PD2 & 0.50 & 0.21 & $0.37^{\star \star}$ & $0.70^{\star *}$ & $0.63^{\star \star}$ & 0.09 & 0.33 & 0.03 & $0.39^{\star \star}$ \\
\hline PS1 & $1.51^{\star}$ & 0.93 & $0.75^{\star \star}$ & $1.66^{\star \star}$ & $1.51^{\star \star}$ & 0.19 & 0.80 & 0.31 & $0.63^{\star \star}$ \\
\hline PS2 & 0.51 & 0.19 & $0.42^{\star}$ & $1.23^{\star *}$ & $1.18^{\star \star}$ & 0.06 & 0.49 & 0.05 & $0.56^{\star \star}$ \\
\hline PA1 & $1.34^{\star}$ & 1.13 & 0.27 & $1.44^{\star \star}$ & $1.35^{\star \star}$ & 0.12 & 0.93 & 0.48 & $0.58^{\star \star}$ \\
\hline \multirow[t]{2}{*}{ PA2 } & $1.40^{*}$ & 0.91 & $0.63^{\star \star}$ & $0.98^{\star \star}$ & $0.89^{\star \star}$ & 0.11 & $1.18^{\star *}$ & $0.82^{*}$ & $0.46^{\star \star}$ \\
\hline & \multicolumn{5}{|c|}{ Long/Short Equity Hedge } & \multicolumn{4}{|c|}{ Multistrategy } \\
\hline \multicolumn{2}{|l|}{$\begin{array}{l}\text { Portfolio } \\
\text { Strategy } \\
\end{array}$} & & $\alpha \mathrm{PS}$ & \multicolumn{2}{|c|}{$\beta_{\mathrm{PS}}$} & $\alpha$ & \multicolumn{2}{|c|}{$\alpha \mathrm{PS}$} & $\beta_{\mathrm{PS}}$ \\
\hline ND & & & 0.42 & \multicolumn{2}{|c|}{$0.49^{* \star}$} & $0.76^{\star}$ & \multicolumn{2}{|c|}{0.61} & $0.20^{\star}$ \\
\hline PD1 & & & 0.25 & \multicolumn{2}{|c|}{$0.34^{* *}$} & $0.91^{* *}$ & \multicolumn{2}{|c|}{$0.80^{\star *}$} & 0.15 \\
\hline PD2 & & & $0.65^{\star \star}$ & \multicolumn{2}{|c|}{$0.40^{* *}$} & $0.83^{* *}$ & \multicolumn{2}{|c|}{$0.73^{\star \star}$} & 0.13 \\
\hline PS1 & & & 0.42 & \multicolumn{2}{|c|}{$0.78^{\star *}$} & $2.52^{\star *}$ & \multicolumn{2}{|c|}{$2.50^{\star *}$} & 0.02 \\
\hline PS2 & & & 0.60 & & $1.60^{*}$ & \multicolumn{2}{|c|}{$1.55^{*}$} & 0.06 \\
\hline PA1 & & & 0.18 & \multirow{2}{*}{\multicolumn{2}{|c|}{$0.47^{\star *}$}} & $2.41^{\star *}$ & \multirow{2}{*}{\multicolumn{2}{|c|}{$\begin{array}{l}2.37^{\star} \\
2.65^{\star \star}\end{array}$}} & 0.05 \\
\hline PA2 & & & 0.41 & & & $2.75^{\star *}$ & & & 0.12 \\
\hline
\end{tabular}

Predictability in managerial skills matters the most for portfolios within the emerging markets, equity market-neutral, event-driven, and multistrategy styles that, except for equity market-neutral, can be mapped into the following alternatively defined hedge fund styles: directional trader and multiprocess. ${ }^{13}$ Avramov et al. (2007), (2011) obtain similar results. However, unlike Avramov et al., our results show that incorporating predictability in managerial skills may also improve the performance of the relative value (equity market-neutral) style-based portfolios.

The performance analysis has so far ignored an important risk factor to which many hedge funds may be exposed, namely, systematic liquidity risk. How does systematic liquidity risk affect the performance of these portfolios? Can an omitted liquidity risk premium explain part of the outperformance of the portfolio strategies incorporating predictability in managerial skills? To answer these questions, let us look at Table 4, which also reports the alphas and the liquidity risk

\footnotetext{
${ }^{12}$ Within the long/short equity hedge fund style, none of the agnostic and skeptic portfolios generates significant alpha at the 5\% level, although the alphas of the portfolios PS1 and PS2 are larger than those of the dogmatic portfolios. However, if we also consider the $10 \%$ significance level, then the alpha generated by the portfolio PS1 is significant.

${ }^{13}$ See Appendix A in Agarwal, Daniel, and Naik (2005).
} 
factor betas in the performance evaluation model enlarged with the liquidity risk factor $\mathrm{LIQ}^{\mathrm{PS}}$.

The evaluation results obtained when including the liquidity risk factor as an additional explanatory variable can be summarized as follows: The estimated liquidity risk factor beta $\beta_{\mathrm{PS}}$ is positive and significant at least at the $5 \%$ level for almost all the portfolios belonging to the emerging markets, event-driven, and long/short equity hedge fund styles, with a unique exception for the emerging markets fund portfolio PA1. Furthermore, when the effect of liquidity risk is taken into account, the alphas are reduced to insignificant levels for almost all these styles of portfolios. This result holds whether predictability in managerial skills is incorporated or not. Indeed, the number of significant alphas declines by $30 \%$ (from 20 to 14) once liquidity risk is accounted for. ${ }^{14}$ Unreported bootstrap results show that for 31 out of the 35 hedge fund portfolios, the reduction in the alphas observed after accounting for liquidity risk is statistically significant. ${ }^{15}$

In particular, for the emerging markets funds, when liquidity risk is accounted for, the portfolios that incorporate predictability in managerial skills do not perform better than their dogmatic counterparts, and the alphas generated by the portfolios PS1, PA1, and PA2 all become insignificant. For the event-driven funds, the alpha generated by the portfolio ND becomes insignificant, while the alpha of the portfolio PA2 declines by about $30 \%$, although PA2 is the unique portfolio whose alpha remains significant after considering the effect of liquidity risk. Similarly, within the long/short equity hedge fund style, the alpha generated by the portfolios PD1 and PD2, respectively, becomes insignificant and declines by more than $30 \%$.

A potential explanation for these results is that hedge funds within the emerging markets, event-driven, and long/short equity hedge fund styles use stocks and operate in market segments that bear a significant exposure to liquidity risk. Therefore, it is not surprising that investors require a liquidity risk premium when investing in these types of hedge funds.

Finally, we observe that for the equity market-neutral and multistrategy fund portfolios, the effect of liquidity risk is much weaker: Their estimated liquidity risk factor betas $\beta_{\mathrm{PS}}^{\mathrm{HL}}$ are mostly insignificant, and their alphas remain highly significant (albeit slightly lower). As will be shown later, the significant alphas of the equity market-neutral fund portfolios may be attributed to rents for liquidity provision.

\footnotetext{
${ }^{14}$ The percentage is higher $(37.5 \%)$ when we consider the $10 \%$ significance level. The same remark applies to the results obtained in Section IV.D.

${ }^{15}$ Each calendar date, we use the block bootstrap method to resample each hedge fund portfolio's returns and the Hasanhodzic and Lo (2007) benchmark factors. With the resampled data, we evaluate the performance of portfolios using the Hasanhodzic and Lo model with and without the liquidity risk factor $\mathrm{LIQ}^{\mathrm{PS}}$. In this way, we obtain two series of alphas, one before and one after accounting for liquidity risk. The resampling is repeated 1,000 times. With two sets of 1,000 resampled alphas, we use a paired $t$-test at the $5 \%$ significance level to check whether accounting for liquidity risk can significantly reduce the abnormal performance of the portfolios. The reduction is statistically significant for 31 out of the 35 hedge fund portfolios. When using the Fung and Hsieh (2004) model, the reduction in alphas is statistically significant in 29 out of the 35 portfolios considered.
} 


\section{Robustness Tests}

\section{Fung and Hsieh Seven-Factor Model}

To enable a more direct comparison between the performance of our portfolios with that of the portfolios originally formed by Avramov et al. (2007), (2011), we evaluate the performance of the optimal hedge fund portfolios using the FH7 (2004) model with (and without) the liquidity risk factor:

$$
\begin{aligned}
r_{i, t}= & \alpha_{i}+\beta_{i, 1} \mathrm{SP}_{000}+\beta_{i, 2} \mathrm{SCMLC}_{t}+\beta_{i, 3} \text { 10Y }_{t}+\beta_{i, 4} \mathrm{CRED}_{-} \mathrm{SPR}_{t} \\
& +\beta_{i, 5} \mathrm{BD}_{-} \mathrm{OPT}_{t}+\beta_{i, 6} \mathrm{FX}_{-} \mathrm{OPT}_{t}+\beta_{i, 7} \mathrm{COM}_{-} \mathrm{OPT}_{t}+v_{i, t},
\end{aligned}
$$

where SP500 = the S\&P 500 index excess return; SCMLC $=$ the Wilshire Small Cap 1750 - Wilshire Large Cap 750 return; 10Y = the month-end to month-end change in the U.S. Federal Reserve 10-year constant-maturity yield; CRED_SPR = the month-end to month-end change in the difference between the Moody's Baa yield and the Federal Reserve's 10-year constant-maturity yield; BD_OPT = the return of a portfolio of lookback straddles on bond futures; FX_OPT = the return of a portfolio of lookback straddles on currency futures; and COM_OPT = the return of a portfolio of lookback straddles on commodity futures. The three risk factors of BD_OPT, FX_OPT, and COM_OPT are included to capture the fact that hedge fund returns relate to option-based strategy returns. ${ }^{16}$

The size factor SCMLC and the liquidity risk factor $\mathrm{LIQ}^{\mathrm{PS}}$ are correlated with a correlation coefficient reaching 0.42 . Thus, in order to abstract from multicollinearity in the performance evaluation framework of Fung and Hsieh (2004) augmented for liquidity risk, we regress the liquidity risk factor on the size factor and then use the innovations as the liquidity risk factor proxy denoted by LIQ ${ }^{\mathrm{INN}}$.

The estimated alphas and liquidity risk factor betas in this alternative performance evaluation model and in its extended version are presented in Panel A of Table 5. In the Fung and Hsieh (2004) model without LIQ ${ }^{\mathrm{INN}}$, the alphas of the optimal hedge fund portfolios are generally lower than those obtained in the Hasanhodzic and Lo (2007) model. For example, for the emerging markets and long/short equity hedge funds, neither agnostic nor skeptic investors deliver significant positive alphas.

Similarly to the results obtained in the last subsection, the significance of the liquidity risk factor beta varies across hedge fund styles: For most portfolios belonging to the event-driven and long/short equity hedge fund styles, the estimated liquidity risk factor beta is significantly positive. It is also easy to observe that the estimated liquidity risk factor beta is generally lower and less significant in the enlarged Fung and Hsieh (2004) model. This pattern is due to the fact that the liquidity risk factor is adjusted by the size factor. ${ }^{17}$ A block bootstrap analysis, as described in footnote 15, shows that within the enlarged Fung and Hsieh (2004)

\footnotetext{
${ }^{16}$ For parsimony, we do not report the coefficients of BD_OPT, FX_OPT, and COM_OPT.

${ }^{17}$ If we use the liquidity risk factor $\mathrm{LIQ}^{\mathrm{PS}}$ rather than its innovations and abstract from the size factor in the augmented Fung and Hsieh (2004) evaluation model, we obtain quite similar liquidity risk factor betas as in the enlarged Hasanhodzic and Lo (2007) model. These results are available from the authors.
} 
TABLE 5

Robustness Tests

Table 5 reports, within each of the equity hedge fund styles of emerging markets, equity market-neutral, event-driven, long/short equity hedge, and multistrategy, the results of three robustness tests for the portfolio performance analysis: The first robustness test, in Panel A, is to evaluate the portfolio performance using the Fung and Hsieh (2004) model; the second robustness test, in Panel B, is based on the liquidity risk factor LIQ with hedge funds of which returns are winsorized at the $95 \%$ level to control the effect of outliers. Here, $\alpha$ is the alpha obtained by regressing portfolios' excess returns on the evaluation model benchmarks; $\alpha$ LIO is the same alpha, but adjusted for liquidity risk premium; and $\beta\left\llcorner\mathrm{LQ}\right.$ is the coefficient of the liquidity risk factor in the extended evaluation models. ${ }^{* *}$ and ${ }^{*}$ denote significance at the $1 \%$ and $5 \%$ levels, respectively.

$$
\text { Emerging Markets }
$$

Portfolio Strategy (a)

\section{Panel A. Fung and Hsieh Model}

$\begin{array}{lrr}\text { ND } & -0.17 & -0.52 \\ \text { PD1 } & 0.25 & 0.05 \\ \text { PD2 } & 0.16 & 0.04 \\ \text { PS1 } & 0.91 & 0.67 \\ \text { PS2 } & -0.11 & -0.09 \\ \text { PA1 } & 1.00 & 1.04 \\ \text { PA2 } & 0.94 & 0.70\end{array}$

\section{$\beta_{\mathrm{LIQ}}$} Equity Market-Neutral

$0.52^{\star}$
0.30
0.17
0.36
-0.03
-0.06

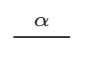

$\underline{\alpha \mathrm{LIQ}}$

$\begin{array}{lll}0.14 & -0.11 & 0.38^{* *}\end{array}$

$\begin{array}{ll}0.14 & -0.11 \\ 0.65^{\star \star} & 0.60^{\star *}\end{array}$

$0.65^{\star \star}$

$1.42^{* *}$

$0.92^{\star *}$

PA2

0.35

$1.22^{\star \star}$
$0.98^{\star \star}$

Panel B. Amihud Liquidity Measure

$\begin{array}{lll}\text { ND } & 0.11 & -0 . \\ \text { PD1 } & 0.61 & 0.30 \\ \text { PD2 } & 0.50 & 0.23 \\ \text { PS1 } & 1.51^{*} & 1.03 \\ \text { PS2 } & 0.51 & 0.25 \\ \text { PA1 } & 1.34^{*} & 1.17 \\ \text { PA2 } & 1.40^{*} & 0.99\end{array}$

-0.38
0.30
0.23
1.03
0.25
1.17
0.99

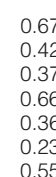

$0.67^{\star \star} \quad 0.29$

$0.42^{* *} \quad 0.81^{* *}$

$\begin{array}{ll}0.86^{* *} & 0.70^{* *} \\ 0.66^{* *} & 1.63^{* *}\end{array}$

$0.36^{*} \quad 1.23^{*}$

$0.23 \quad 1.44^{* *}$

Panel C. Winsorizing Hedge Funds' Returns

\begin{tabular}{llrl} 
ND & 0.39 & -0.10 & $0.62^{\star \star}$ \\
PD1 & $0.83^{*}$ & 0.50 & $0.42^{\star *}$ \\
PD2 & $0.73^{*}$ & 0.50 & $0.29^{\star *}$ \\
PS1 & $1.80^{*}$ & 1.32 & $0.62^{\star *}$ \\
PS2 & 0.47 & 0.10 & $0.48^{*}$ \\
PA1 & 1.16 & 1.00 & 0.20 \\
PA2 & $1.46^{* *}$ & $1.08^{*}$ & $0.50^{* \star}$ \\
\hline
\end{tabular}

\section{$\underline{\beta_{\llcorner I Q}}$}

$0.49^{* *}$
$1.34^{* *}$

$1.34^{* \star}$
$0.84^{\star *}$
$1.10^{* *}$

$1.10^{\star \star}$

0.08
0.12
0.12
0.11
0.18

Event-Driven

\begin{tabular}{|c|c|}
\hline$\alpha$ & $\alpha_{\mathrm{LIQ}}$ \\
\hline 0.33 & \\
\hline 0.20 & $\begin{array}{l}0.19 \\
0.04\end{array}$ \\
\hline 0.17 & $\begin{array}{r}-0.03 \\
-0.03\end{array}$ \\
\hline 0.63 & 0.34 \\
\hline 0.43 & 0.16 \\
\hline 0.69 & 0.42 \\
\hline
\end{tabular}

0.08
$0.79^{* *}$
$0.65^{* *}$
$1.53^{*}$
$1.13^{*}$
$1.30^{*}$
$0.92^{*}$

$0.28^{\star \star}$
0.03
0.07
0.18
0.13
0.18
0.07

$0.60^{*}$
0.38
0.33
0.80
0.49
0.93
$1.18^{\star *}$

0.07

$0.64^{* *}$

$0.64^{* *}$

$1.54^{* *}$
$1.18^{* *}$
$1.42^{* *}$

$1.42^{* *}$
$0.95^{* *}$
Long/Short Equity Hedge

Multistrategy

\begin{tabular}{|c|c|c|c|c|c|c|}
\hline$\beta_{\mathrm{LIQ}}$ & $\alpha$ & $\alpha_{\mathrm{LIQ}}$ & $\beta_{\mathrm{LIQ}}$ & $\alpha$ & $\alpha_{\mathrm{LIQ}}$ & $\beta_{\mathrm{LIQ}}$ \\
\hline $0.20^{\star}$ & 0.27 & 0.09 & 0.27 & 0.47 & 0.27 & $0.28^{*}$ \\
\hline $0.24^{* *}$ & 0.33 & 0.19 & $0.21^{*}$ & $0.77^{\star \star}$ & $0.66^{\star *}$ & 0.17 \\
\hline $0.30^{* *}$ & $0.82^{\star \star}$ & $0.59^{*}$ & $0.34^{* *}$ & $0.77^{\star \star}$ & $0.71^{\star \star}$ & 0.09 \\
\hline $0.44^{* *}$ & 0.62 & 0.40 & 0.32 & $2.43^{\star \star}$ & $2.51^{\star \star}$ & -0.12 \\
\hline $0.41^{\star *}$ & 0.21 & 0.05 & 0.24 & $1.64^{* \star}$ & $1.72^{* \star}$ & -0.12 \\
\hline 0.39 & 0.62 & 0.47 & 0.22 & $2.33^{* \star}$ & $2.43^{* \star}$ & -0.16 \\
\hline $0.31^{* *}$ & 0.60 & 0.38 & 0.31 & $2.54^{* *}$ & $2.64^{\star \star}$ & -0.15 \\
\hline $0.23^{\star \star}$ & 0.79 & 0.57 & $0.31^{*}$ & $0.76^{*}$ & $0.71^{*}$ & 0.08 \\
\hline $0.31^{* *}$ & $0.51^{*}$ & 0.32 & $0.27^{\star \star}$ & $0.91^{\star *}$ & $0.85^{\star *}$ & 0.09 \\
\hline $0.35^{* *}$ & $0.96^{* *}$ & $0.74^{\star \star}$ & $0.30^{\star \star}$ & $0.83^{\star \star}$ & $0.73^{\star *}$ & $0.14^{*}$ \\
\hline $0.45^{\star *}$ & 1.02 & 0.53 & $0.68^{* \star}$ & $2.52^{\star \star}$ & $2.47^{\star \star}$ & 0.06 \\
\hline $0.43^{* *}$ & 1.18 & 0.77 & 0.55 & $1.60^{\star}$ & $1.49^{\star}$ & 0.15 \\
\hline $0.41^{* *}$ & 0.54 & 0.26 & $0.39^{* \star}$ & $2.41^{* \star}$ & $2.33^{*}$ & 0.10 \\
\hline $0.35^{* *}$ & 0.85 & 0.48 & $0.50^{* \star}$ & $2.75^{\star *}$ & $2.58^{\star \star}$ & 0.23 \\
\hline $0.34^{* *}$ & 0.85 & 0.47 & $0.49^{* *}$ & $0.89^{* *}$ & $0.77^{*}$ & 0.15 \\
\hline $0.30^{* *}$ & $0.54^{*}$ & 0.28 & $0.33^{* \star}$ & $0.88^{* *}$ & $0.81^{* *}$ & 0.09 \\
\hline $0.32^{* *}$ & $1.05^{\star *}$ & $0.77^{\star \star}$ & $0.35^{\star \star}$ & $0.85^{* *}$ & $0.79^{\star *}$ & 0.08 \\
\hline $0.65^{* *}$ & $1.20^{*}$ & 0.69 & $0.65^{\star \star}$ & $2.28^{\star \star}$ & $2.24^{\star \star}$ & 0.06 \\
\hline $0.24^{*}$ & 1.11 & 0.71 & $0.51^{*}$ & $1.40^{\star \star}$ & $1.33^{\star}$ & 0.09 \\
\hline $0.53^{\star *}$ & 0.65 & 0.32 & $0.42^{\star}$ & $2.13^{\star \star}$ & $2.12^{\star \star}$ & 0.01 \\
\hline $0.42^{* *}$ & 0.83 & 0.44 & $0.50^{* \star}$ & $2.38^{\star *}$ & $2.20^{\star \star}$ & 0.24 \\
\hline
\end{tabular}


performance model, liquidity risk significantly reduces the alphas of 29 out of the 35 hedge fund portfolios.

\section{Amihud Liquidity Measure}

We next examine whether our results are robust to alternative liquidity risk measures. In the following, we conduct the previous performance evaluation using the extended Hasanhodzic and Lo (2007) model obtained by including the Amihud (2002) liquidity risk factor LIQ ${ }^{\mathrm{AMH}}$ in equation (4).

The results with the liquidity risk factor $\mathrm{LIQ}^{\mathrm{AMH}}$ reported in Panel B of Table 5 are similar to those that we obtained in Section V.C, although the Amihud (2002) liquidity risk factor's impact is smaller in most cases. Particularly, the reduction in the number of significant alphas is only slightly less strong (5 out of 20 alphas become insignificant at the $5 \%$ level). This result is not surprising, given that the liquidity risk factors $\mathrm{LIQ}^{\mathrm{PS}}$ and $\mathrm{LIQ}^{\mathrm{AMH}}$ are highly and positively correlated, as mentioned previously.

\section{Winsorizing Hedge Funds' Returns}

It is well known that the distribution of many hedge funds' returns displays heavy tails. We thus investigate whether extreme hedge funds' returns could in part explain the role that we attribute to liquidity risk in reducing the abnormal performance of the optimal hedge fund portfolios. We test this hypothesis by using individual hedge fund returns winsorized at the $95 \%$ level. ${ }^{18}$

Comparing the results displayed in Panel C of Table 5 with those in Table 4, we observe that how winsorization affects the hedge fund portfolios' raw alphas is closely related to the skewness of their returns. The negative skewness of the emerging markets or event-driven portfolios' returns reported in Table 2 implies that the returns of the individual hedge funds embedded in these portfolios also exhibit negative skewness. Thus, winsorizing the individual hedge funds' returns for these two styles of portfolios tends to mainly exclude the effect of extreme losses and shifts these hedge fund portfolios' raw alphas up.

When accounting for liquidity risk, we observe that, as in the case without winsorization, the liquidity risk factor betas are significantly positive for almost all the portfolios belonging to the emerging markets, event-driven, and long/short equity hedge fund styles. Likewise, the estimated alphas for $32 \%$ of the portfolios are reduced to insignificant levels when liquidity risk is accounted for. Once again, liquidity risk only bears a limited impact on the performance of the equity marketneutral and multistrategy styles-based portfolios. Overall, winsorizing hedge fund returns does not alter our main conclusions regarding the role played by liquidity risk in explaining equity hedge fund portfolios' abnormal performance. ${ }^{19}$

\footnotetext{
${ }^{18} \mathrm{~A} 95 \%$ winsorization would see all hedge funds' returns below the 2.5 th percentile set to the 2.5th percentile, and all hedge funds' returns above the 97.5 th percentile set to the 97.5 th percentile. A $90 \%$ winsorization of the hedge funds' returns generated similar results.

${ }^{19}$ Our empirical results are also robust to the exclusion of the month of January hedge fund return series and to the impact of the return smoothing undertaken by some hedge fund managers. Additional robustness tests performed to account for these two issues are available from the authors.
} 


\section{E. Financial Crises and the Effect of Liquidity Risk}

We now check whether the lack of superior performance documented so far for many optimal portfolios once we account for liquidity risk is mainly driven by large discontinuous liquidity shocks experienced by hedge funds during financial crises. To test this hypothesis, we run the performance estimation regressions during the sample period, while excluding the months of July 1997, August and September 1998, and March 2000, when the following financial crises, respectively, occurred: the Asian financial crisis, the Russian Government bond default and the following debacle of LTCM, and the bursting of the dot.com bubble.

The estimation results are reported in Table 6. This table indicates that for all but equity market-neutral styles-based portfolios, the estimated alphas before accounting for the effect of liquidity risk when the return data over the financial crisis periods are excluded are higher than those reported in Table 4 (we now observe 27 significant alphas over the same period). This result is not surprising, since these styles-based portfolios suffered large losses during the financial crises (particularly during the Russian financial crisis and the debacle of LTCM); thus, their estimated alphas are less eroded when the return data over these crisis periods are ignored. Second, the estimated coefficients of the liquidity risk factor $\mathrm{LIQ}^{\mathrm{PS}}$ are again significantly positive for most portfolios belonging to the emerging markets, event-driven, and long/short equity hedge fund styles, although they are generally lower than those displayed in Table 4. Third, the effect of liquidity risk on the alphas of all styles-based portfolios is stronger than the one

\section{TABLE 6}

Financial Crises and the Effect of Liquidity Risk

\begin{tabular}{|c|c|c|c|c|c|c|c|c|c|}
\hline \multirow{2}{*}{$\begin{array}{l}\text { Portfolio } \\
\text { Strategy } \\
\end{array}$} & \multicolumn{3}{|c|}{ Emerging Markets } & \multicolumn{3}{|c|}{ Equity Market-Neutral } & \multicolumn{3}{|c|}{ Event-Driven } \\
\hline & $\alpha$ & $\alpha_{\mathrm{PS}}$ & $\beta_{\mathrm{PS}}$ & $\alpha$ & $\alpha \mathrm{PS}$ & $\beta_{\mathrm{PS}}$ & $\alpha$ & $\alpha \mathrm{PS}$ & $\beta_{\mathrm{PS}}$ \\
\hline $\begin{array}{l}\text { ND } \\
\text { PD1 } \\
\text { PD2 } \\
\text { PS1 } \\
\text { PS2 } \\
\text { PA1 } \\
\text { PA2 }\end{array}$ & $\begin{array}{l}0.72 \\
0.90^{\star} \\
0.79^{\star} \\
1.77^{\star} \\
0.74 \\
1.36 \\
1.82^{\star \star}\end{array}$ & $\begin{array}{l}0.28 \\
0.60 \\
0.58 \\
1.27 \\
0.46 \\
1.18 \\
1.40^{\star}\end{array}$ & $\begin{array}{l}0.50^{\star \star} \\
0.35^{\star \star} \\
0.23^{\star} \\
0.57^{\star} \\
0.32 \\
0.21 \\
0.47^{\star \star}\end{array}$ & $\begin{array}{l}0.28 \\
0.75^{\star \star} \\
0.64^{\star \star} \\
1.62^{\star \star} \\
1.15^{\star \star} \\
1.36^{\star \star} \\
0.86^{\star \star}\end{array}$ & $\begin{array}{c}-0.04 \\
0.72^{\star \star} \\
0.58^{\star \star} \\
1.48^{\star \star} \\
1.09^{\star \star} \\
1.25^{\star \star} \\
0.76^{\star \star}\end{array}$ & $\begin{array}{l}0.36^{\star \star} \\
0.03 \\
0.07 \\
0.16 \\
0.07 \\
0.12 \\
0.11\end{array}$ & $\begin{array}{l}0.80^{\star *} \\
0.58^{\star \star} \\
0.54^{\star} \\
0.90^{\star} \\
0.57 \\
0.99 \\
1.29^{\star \star}\end{array}$ & $\begin{array}{l}0.55^{\star} \\
0.32 \\
0.26 \\
0.33 \\
0.06 \\
0.46 \\
0.91^{\star \star}\end{array}$ & $\begin{array}{l}0.29^{\star \star} \\
0.30^{\star \star} \\
0.32^{\star \star} \\
0.65^{\star \star} \\
0.57^{\star \star} \\
0.61^{\star \star} \\
0.43^{\star \star}\end{array}$ \\
\hline PA2 & \multicolumn{5}{|c|}{ Long/Short Equity Hedge } & \multicolumn{4}{|c|}{ Multistrategy } \\
\hline \multicolumn{9}{|l|}{ Portfolio } & $\beta \mathrm{PS}$ \\
\hline $\begin{array}{l}\text { ND } \\
\text { PD1 } \\
\text { PD2 } \\
\text { PS1 } \\
\text { PS2 } \\
\text { PA1 } \\
\text { PA2 }\end{array}$ & & & $\begin{array}{l}0.72 \\
0.30 \\
0.71^{\star *} \\
0.67 \\
0.61 \\
0.24 \\
0.56\end{array}$ & & $\begin{array}{l}4^{\star} \\
0^{\star \star} \\
4^{\star \star} \\
9^{\star \star} \\
7^{\star \star} \\
0^{\star \star} \\
9^{\star \star}\end{array}$ & $\begin{array}{l}0.87^{\star \star} \\
1.02^{\star \star} \\
0.93^{\star \star} \\
2.64^{\star \star} \\
1.74^{\star \star} \\
2.54^{\star \star} \\
2.71^{\star \star}\end{array}$ & & & $\begin{array}{r}0.18 \\
0.12 \\
0.10 \\
-0.05 \\
0.00 \\
-0.04 \\
0.10\end{array}$ \\
\hline
\end{tabular}


in Section V.C, since 37\% (10 out of 27 portfolios' alphas) of them now become insignificant.

Following these results, we can conclude that financial crises were not the only systematic liquidity events that have affected the performance of these equity hedge fund portfolios. The empirical results presented so far indicate that frequent yet small systematic liquidity shocks significantly affect most equity hedge fund portfolios' performance.

\section{F. Liquidity Risk Premium versus Rents for Liquidity Provision}

Unlike many traditional investment instruments, hedge funds have so far been less prone to regulation (e.g., they have until recently not been required to disclose their positions to investors or to financial authorities). As argued by Miller (2010), one possible explanation for the regulatory forbearance of hedge funds may arise from the need to allow these funds to provide liquidity to financial markets. As a compensation, it would seem natural that hedge funds then earn rents for providing liquidity. Rents for liquidity provision are clearly distinct from earning a systematic liquidity risk premium, which has so far been the focus of this study. To study whether all or some equity hedge funds may also earn rents from providing liquidity and to disentangle the rents for liquidity provision from the premia compensated for liquidity risk bearing, we conduct an indirect test of the liquidity provision rents hypothesis. For that purpose, let us consider two subsample periods: the first covering the period from Jan. 1998 to Dec. 2001, and the second covering the period from Jan. 2003 to Dec. 2006. As particularly shown in Graph B of Figure 1, which plots the evolution of the Amihud (2002) liquidity measure, the first period can be deemed much less liquid than the second period. Figure 2 plots the TED spread, defined as the difference between the 3-month Eurodollar deposit rate and the 3-month T-bill interest rate during the period from Jan. 1996 to Dec. 2006. The TED spread is regarded as a proxy for the funding cost faced by market participants. We observe that, during the first so-called illiquid period, the TED spread was much higher, meaning that funding was much more expensive during that period. We choose Jan. 2003 as the starting month of

FIGURE 2

TED Spread

Figure 2 plots a series of monthly TED spread, which is defined as the 3-month Eurodollar deposit rate minus the 3-month T-bill interest rate, during the period between Jan. 1996 and Dec. 2006

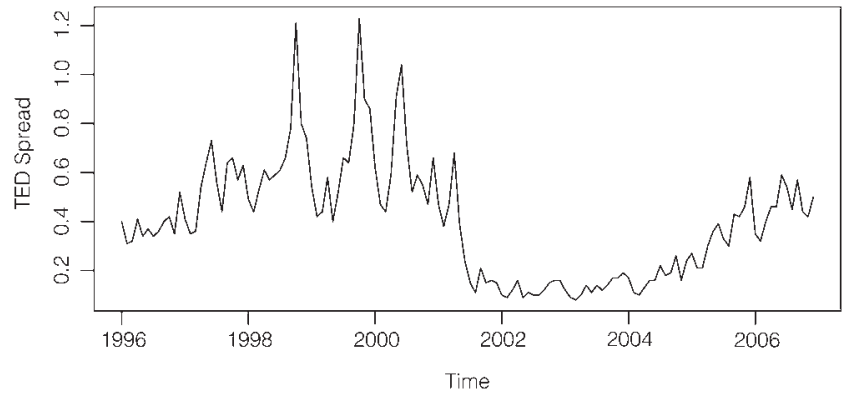


the second period because the importance of hedge funds as liquidity providers was reduced following the gradual introduction of the Autoquote system on the NYSE in 2003, as documented in Jylha et al. (2011). If some hedge funds provide liquidity to financial markets and are compensated for this through liquidity rents assimilated to residual alphas (after accounting for liquidity risk), then they should earn higher rents (i.e., residual alphas) during the first period when liquidity was low. Jylha et al. show that the equity market-neutral, event-driven, and long/short equity hedge funds generally act as liquidity suppliers. They do not, however, document any similar pattern for the emerging markets and multistrategy hedge funds. Thus, we should observe that these former three categories of hedge funds earned higher residual alphas during the first "illiquid" period.

Table 7 reports the residual alphas (after accounting for liquidity risk) and the liquidity risk factor betas of the optimal hedge fund portfolios during both subperiods. We observe that the portfolios within the emerging markets and eventdriven styles earn much higher excess returns in the second period, while the equity market-neutral and long/short equity hedge fund styles-based portfolios perform much better during the first period. ${ }^{20}$ Thus, and consistent with

TABLE 7

Out-of-Sample Performance of Portfolio Strategies in Different Periods

Table 7 reports, within each of the equity hedge fund styles of emerging markets, equity market-neutral, event-driven, long/short equity hedge, and multistrategy, the alphas of the portfolios that are optimal from the perspective of the seven types of investors as described in the context and the coefficients of the liquidity risk factor LIQPS constructed from the Pastor and Stambaugh (2003) liquidity measure. The portfolio performance evaluation is conducted over two subperiods: from Jan. 1998 to Dec. 2001 (P1) and from Jan. 2003 to Dec. 2006 (P2). Here, $\alpha$ PS is the $i$ th period's alpha estimated in the extended Hasanhodzic and Lo (2007) model, and $\beta_{\mathrm{PS}}^{i}$ is the $i$ th period's coefficient of the liquidity risk factor LIQPS ${ }^{* *}$ and ${ }^{*}$ denote significance at the $1 \%$ and $5 \%$ levels, respectively.

\begin{tabular}{|c|c|c|c|c|c|c|c|c|c|c|c|c|}
\hline \multirow[b]{3}{*}{$\begin{array}{l}\text { Portfolio } \\
\text { Strategy }\end{array}$} & \multicolumn{4}{|c|}{ Emerging Markets } & \multicolumn{4}{|c|}{ Equity Market-Neutral } & \multicolumn{4}{|c|}{ Event-Driven } \\
\hline & \multicolumn{2}{|c|}{ P1 } & \multicolumn{2}{|c|}{ P2 } & \multicolumn{2}{|c|}{$\mathrm{P} 1$} & \multicolumn{2}{|c|}{ P2 } & \multicolumn{2}{|c|}{ P1 } & \multicolumn{2}{|c|}{ P2 } \\
\hline & $\alpha_{\mathrm{PS}}^{1}$ & $\beta_{\mathrm{PS}}^{1}$ & $\alpha_{P S}^{2}$ & $\beta_{\mathrm{PS}}^{2}$ & $\alpha_{\mathrm{PS}}^{1}$ & $\beta_{\mathrm{PS}}^{1}$ & $\alpha_{P S}^{2}$ & $\beta_{\mathrm{PS}}^{2}$ & $\alpha_{P S}^{1}$ & $\beta_{\mathrm{PS}}^{1}$ & $\alpha_{\mathrm{PS}}^{2}$ & $\beta_{\mathrm{PS}}^{2}$ \\
\hline ND & -1.12 & $0.99^{\star \star}$ & 0.85 & 0.31 & 0.49 & $0.25^{*}$ & -0.37 & 0.14 & 0.56 & $0.48^{\star \star}$ & 0.43 & 0.36 \\
\hline PD1 & -0.12 & $0.81^{\star \star}$ & $1.27^{*}$ & 0.20 & $0.98^{\star *}$ & -0.03 & -0.06 & 0.27 & 0.32 & $0.38^{\star \star}$ & -0.37 & 0.21 \\
\hline PD2 & 0.06 & $0.61^{\star \star}$ & 0.91 & -0.06 & $0.67^{\star}$ & 0.02 & -0.06 & 0.24 & 0.30 & $0.34^{\star \star}$ & -0.36 & $0.30^{\star}$ \\
\hline PS1 & -0.57 & $0.99^{\star \star}$ & $3.05^{\star}$ & 0.06 & $2.12^{\star \star}$ & 0.06 & 0.76 & 0.36 & -0.67 & $0.66^{* \star}$ & 1.73 & 0.07 \\
\hline PS2 & $-2.60^{*}$ & 0.38 & $3.68^{\star \star}$ & -0.14 & $0.98^{*}$ & -0.11 & $1.13^{*}$ & 0.15 & -0.59 & $0.83^{* *}$ & $1.35^{\star}$ & 0.18 \\
\hline PA1 & -0.06 & 0.51 & $3.45^{\star}$ & -0.06 & 1.06 & -0.12 & 0.95 & 0.48 & $-2.47^{\star \star}$ & $0.43^{*}$ & $3.06^{\star}$ & -0.28 \\
\hline \multirow[t]{3}{*}{ PA2 } & -0.60 & $0.77^{\star \star}$ & $3.89^{\star \star}$ & 0.02 & 0.83 & 0.01 & 0.71 & 0.33 & 0.05 & $0.27^{* *}$ & $1.73^{*}$ & 0.29 \\
\hline & \multicolumn{6}{|c|}{ Long/Short Equity Hedge } & \multicolumn{6}{|c|}{ Multistrategy } \\
\hline & \multicolumn{3}{|c|}{ P1 } & \multicolumn{3}{|c|}{$\mathrm{P} 2$} & \multicolumn{3}{|c|}{ P1 } & \multicolumn{3}{|c|}{$\mathrm{P} 2$} \\
\hline $\begin{array}{l}\text { Portfolio } \\
\text { Strategy } \\
\end{array}$ & & 1 PS & $\beta_{\mathrm{PS}}^{1}$ & & $\alpha_{P S}^{2}$ & $\beta_{\mathrm{PS}}^{2}$ & & & $\beta_{\mathrm{PS}}^{1}$ & & $\alpha_{P S}^{2}$ & $\beta_{\mathrm{PS}}^{2}$ \\
\hline ND & & 61 & $0.77^{\star \star}$ & & -0.29 & 0.37 & 1.0 & & $0.32^{*}$ & & 0.44 & 0.05 \\
\hline PD1 & & $14^{* *}$ & $0.42^{\star \star}$ & & -0.26 & 0.31 & & $8^{* *}$ & $0.26^{\star}$ & & 0.87 & -0.01 \\
\hline PD2 & & $73^{* *}$ & $0.42^{\star \star}$ & & 0.00 & 0.30 & & & 0.19 & & 0.85 & 0.01 \\
\hline PS1 & & $33^{*}$ & $1.00^{\star \star}$ & & -0.50 & 0.69 & & & 0.03 & & $4.69^{*}$ & 0.06 \\
\hline PS2 & & & 0.92 & & 0.23 & -0.39 & & $8^{* *}$ & 0.22 & & 2.50 & -0.03 \\
\hline PA1 & & 72 & 0.48 & & -0.36 & 0.69 & & $9^{*}$ & 0.02 & & 3.93 & 0.37 \\
\hline PA2 & & $78^{*}$ & $0.45^{\star}$ & & -0.85 & 0.60 & & $8^{* *}$ & 0.25 & & $6.29^{\star}$ & -0.61 \\
\hline
\end{tabular}

\footnotetext{
${ }^{20}$ The multistrategy fund portfolios excluding predictability in managerial skills perform better during the first subperiod, while the multistrategy fund portfolios incorporating predictability in managerial skills tend to perform surprisingly well during the second subperiod.
} 
Jylha et al. (2011), the equity market-neutral and long/short equity hedge funds seem to earn liquidity provision rents (identified as their high and significant residual alphas) during the first period, while clearly their residual performance is much weaker (and generally insignificant) during the second period, when they were less needed as liquidity providers. The evidence supporting these results is reinforced once we note that these two style portfolios also earn high and significant residual alphas even when we do not account for any source of managerial skills' predictability in their returns. Our results, however, stand in contrast with those from Jylha et al. (2011) as far as the event-driven funds are concerned, since we observe that their residual alphas are usually higher and significant during the second period (when liquidity was high).

\section{Conclusion}

In this article, we study the effect of liquidity risk on the performance of the optimal portfolio strategies for equity hedge funds. Similarly to Avramov et al. (2007), (2011), we observe that, before accounting for the effect of systematic liquidity risk, hedge fund portfolios that incorporate predictability in managerial skills generate superior performance. However, this outperformance disappears or weakens substantially for most emerging markets, event-driven, and long/short equity hedge fund portfolios once the impact of liquidity risk is incorporated into the performance evaluation framework of Hasanhodzic and Lo (2007). In other words, for these equity hedge fund styles-based portfolios incorporating predictability in managerial skills, "alphas" in part reflects compensation for systematic liquidity risk bearing. These results hold under various robustness tests. We also provide indirect evidence for the fact that the residual alphas (after accounting for liquidity risk) of the equity market-neutral and long/short equity hedge fund portfolios may be attributed to the rents earned by these two categories of hedge funds from providing liquidity during time periods when it is most needed.

This study only focuses on equity hedge funds. As shown in a previous version of this article, the effect of liquidity risk is weaker for some nonequity (e.g., fixed income arbitrage and managed futures) hedge funds. This may be attributed to the fact that these hedge funds do not respond or covary with a liquidity risk factor constructed with equity data. In the future, it would be worth exploring whether similar liquidity risk factors that are constructed with nonequity securities price and trading volume data can help us explain and disentangle the performance of these broader sets of hedge funds.

\section{Appendix. Bootstrap Method}

The bootstrapped average returns and Sharpe ratios reported in Table 3 are estimated with the block bootstrap method. The block bootstrap is the best-known method for implementing the bootstrap with the time-series autocorrelated data. It consists of dividing the data into blocks of observations and sampling the blocks randomly with replacement. More precisely, let $\left\{r_{p, t}, t=1, \ldots, n\right\}$ be the return observations generated by a hedge fund portfolio $p$. With overlapping blocks of length $l$, block 1 is observations of $\left\{r_{p, s}, s=1, \ldots, l\right\}$, block 2 is observations of $\left\{r_{p, s+1}, s=1, \ldots, l\right\}$, and so forth. The 
bootstrap sample is then obtained by sampling blocks randomly with replacement and laying them end to end in the order sampled. In our block bootstrap procedure, we choose the block length $l=n^{1 / 3}$. Hall and Horowitz (1996) use two block lengths $l=5$ and $l=10$ for two sample sizes $(n=50,100)$, and Inoue and Shintani (2006) select the block length by an automatic procedure that results in an average block length of 3.5 for sample size 64 and 6 for sample size 128. Here, we use a simple rule: The block length in our simulations is similar to the average block length of Inoue and Shintani. For each bootstrap sample, we calculate the average return (Sharpe ratio), and the bootstrapped average return (Sharpe ratio) is the average of the $B(=1,000)$ bootstrapped average return (Sharpe ratio) estimators. Within each hedge fund style, for any two samples of the $B$ bootstrapped average return (Sharpe ratio) estimators, we perform a paired $t$-test at the significance level $5 \%$ to determine which sample comes from a distribution with higher mean, and the highest mean is bolded. The results obtained with other bootstrap methods like resampling the residuals in the fitted Hasanhodzic and Lo (2007) (or Fung and Hsieh (2004)) model are similar and are not reported in Table 2 to save space.

\section{References}

Acharya, V. V., and L. H. Pedersen. "Asset Pricing with Liquidity Risk.” Journal of Financial Economics, 77 (2005), 375-410.

Agarwal, V.; N. D. Daniel; and N. Y. Naik. "Why Is Santa Claus So Kind to Hedge Funds? The December Bonanza Puzzle!” Working Paper, Georgia State University (2005).

Agarwal, V., and N. Y. Naik. "Multi-Period Performance Persistence Analysis of Hedge Funds." Journal of Financial and Quantitative Analysis, 35 (2000), 327-342.

Agarwal, V., and N. Y. Naik. "Risks and Portfolio Decisions Involving Hedge Funds." Review of Financial Studies, 17 (2004), 63-98.

Amihud, Y. "Illiquidity and Stock Returns: Cross-Section and Time-Series Effects." Journal of Financial Markets, 5 (2002), 31-56.

Aragon, G. O. "Share Restrictions and Asset Pricing: Evidence from the Hedge Fund Industry." Journal of Financial Economics, 83 (2007), 33-58.

Avramov, D.; R. Kosowski; N. Y. Naik; and M. Teo. "Investing in Hedge Funds When Returns Are Predictable." Working Paper, University of Maryland (2007).

Avramov, D.; R. Kosowski; N. Y. Naik; and M. Teo. "Hedge Funds, Managerial Skill, and Macroeconomic Variables.” Journal of Financial Economics, 99 (2011), 672-692.

Avramov, D., and R. Wermers. "Investing in Mutual Funds When Returns Are Predictable." Journal of Financial Economics, 81 (2006), 339-377.

Brown, S. J.; W. N. Goetzmann; and R. G. Ibbotson. "Offshore Hedge Funds: Survival and Performance, 1989-95." Journal of Business, 72 (1999), 91-117.

Campbell, J. Y.; S. J. Grossman; and J. Wang. "Trading Volume and Serial Correlation in Stock Returns.” Quarterly Journal of Economics, 108 (1993), 905-939.

Cao, C.; Y. Chen; B. Liang; and A. W. Lo. "Can Hedge Funds Time Market Liquidity?” Journal of Financial Economics, forthcoming (2013).

Fung, W., and D. A. Hsieh. "Empirical Characteristics of Dynamic Trading Strategies: The Case of Hedge Funds." Review of Financial Studies, 10 (1997), 275-302.

Fung, W., and D. A. Hsieh. "The Risk in Hedge Fund Strategies: Theory and Evidence from Trend Followers." Review of Financial Studies, 14 (2001), 313-341.

Fung, W., and D. A. Hsieh. "Hedge Fund Benchmarks: A Risk-Based Approach." Financial Analysts Journal, 60 (2004), 65-80.

Getmansky, M.; A. W. Lo; and I. Makarov. "An Econometric Model of Serial Correlation and Illiquidity in Hedge Fund Returns.” Journal of Financial Economics, 74 (2004), 529-609.

Gibson, R., and N. Mougeot. "The Pricing of Systematic Liquidity Risk: Empirical Evidence from the U.S. Stock Market.” Journal of Banking and Finance, 28 (2004), 157-178.

Hall, P., and J. L. Horowitz. "Bootstrap Critical Values for Tests Based on Generalized-Method-ofMoments Estimators.” Econometrica, 64 (1996), 891-916.

Hasanhodzic, J., and A. W. Lo. "Can Hedge-Fund Returns Be Replicated?: The Linear Case.” Journal of Investment Management, 5 (2007), 5-45.

Inoue, A., and M. Shintani. "Bootstrapping GMM Estimators for Time Series." Journal of Econometrics, 133 (2006), 531-555. 
Jylha, P.; K. Rinne; and M. Suominen. "Do Hedge Funds Supply or Demand Immediacy?” Working Paper, Aalto University (2011).

Kosowski, R.; N. Y. Naik; and M. Teo. "Do Hedge Funds Deliver Alpha? A Bayesian and Bootstrap Analysis.” Journal of Financial Economics, 84 (2007), 229-264.

Kyle, A. S. "Continuous Auctions and Insider Trading.” Econometrica, 53 (1985), 1315-1335.

Liang, B. "On the Performance of Hedge Funds.” Financial Analysts Journal, 55 (1999), 72-85.

Miller, J. I. "Inventing Hedge Funds: A Comparative Study of Institutional and Individual Entrepreneurship in Ambiguously Regulated Environments." PhD Dissertation, New York University (2010).

Pastor, L., and R. F. Stambaugh. "Liquidity Risk and Expected Stock Returns.” Journal of Political Economy, 111 (2003), 642-685.

Sadka, R. "Momentum and Post-Earnings-Announcement Drift Anomalies: The Role of Liquidity Risk." Journal of Financial Economics, 80 (2006), 309-349.

Sadka, R. "Liquidity Risk and the Cross-Section of Hedge-Fund Returns." Journal of Financial Economics, 98 (2010), 54-71. 